Portland State University

PDXScholar

$11-2-1982$

\title{
Attitudes of Mental Health Professional Groups Toward Mental Health Treatment Modalities as Measured by the Semantic Differential Technique
}

Gene Stanley Morrill

Portland State University

Follow this and additional works at: https://pdxscholar.library.pdx.edu/open_access_etds

Part of the Psychiatry and Psychology Commons, and the Psychoanalysis and Psychotherapy Commons

Let us know how access to this document benefits you.

\section{Recommended Citation}

Morrill, Gene Stanley, "Attitudes of Mental Health Professional Groups Toward Mental Health Treatment Modalities as Measured by the Semantic Differential Technique" (1982). Dissertations and Theses. Paper 3224.

https://doi.org/10.15760/etd.3214

This Thesis is brought to you for free and open access. It has been accepted for inclusion in Dissertations and Theses by an authorized administrator of PDXScholar. Please contact us if we can make this document more accessible: pdxscholar@pdx.edu. 
AN ABSTRACT OF THE THESIS OF Gene Stanley Morrill for the Master of Science in Psychology presented November 2, 1982.

Title: Attitudes of Mental Health Professional Groups Toward Mental Health Treatment Modalities as Measured by the Semantic Differential Technique

APPROVED BY MEMBERS OF THE THESIS COMMITTEE:

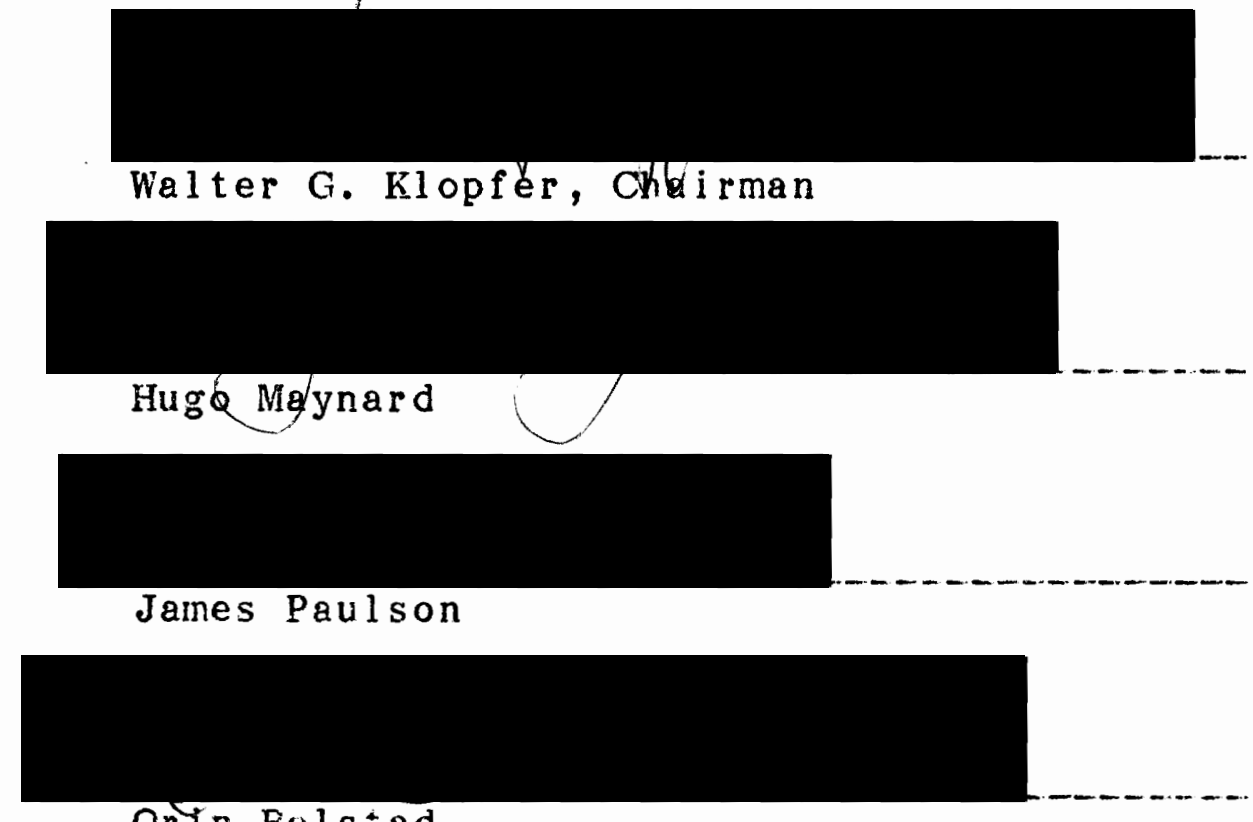

OrIn Bolstad

The present research was conducted in order to ascertain whether differerces in attitudes exist between the three main professicnal groups which are presently the major providers of mental health care -- psychiatrists, clinical 
psychologists, and social workers - - with respect to six treatment modalities: Individual Psychotherapy, Individual Counseling, Family Therapy, Group Therapy, Psychiatric Medication and Psychiatric Hospitalization. Modalities evaluated include treatments appropriate to a variety of individual, social and biological concepts of mental health/pathology. It was assumed that any such at titudinal differences might reflect biases in the provision of mental health treatment and therefore be an important concern for consumers of mental health care.

Hypotheses were: 1) all professional groups would regard Individual Psychotherapy more positively than the other modalities; 2) social workers would regard Family Therapy and Group Therapy more positively than psychiatrists, with clinical psychologists intermediate between these groups; and 3) psychiatrists would regard Psychiatric Medication and Psychiatric Hospitalization more positively than social workers, with clinical psychologists intermediate.

No hypotheses were made regarding intergroup differences with respect to Individual Counseling and Individual Psychotherapy, as a secondary focus of this research was simply to explore possible differences in the ratings of these two modalities in order to gain information about the mental health professionals' perceptions of the distinctness or similarity of these two methods. 
Data were semantic differential (bipolar scale) ratings on an eygluation (attitudinal) dimension for modalities involving hypotheses, as well as potency and eqctiyity dimension ratings for Individual Counseling and Individual Psychotherapy. A random sample of practicing clinicians of the three professions under consideration from the greater metropolitan area of Portland, Oregon was administered the semantic differential scales by mail.

It was found that Individual Psychotherapy was the most favored treatment modality of psychiatrists and psychologists, while social workers preferred it only over Psychiatric Medication and Psychiatric hospitalization. Previous indications of strongly favorable professional attitudes toward Individual Psychotherapy were substantiated, with an additional implication that social workers may be more broadly accepting than the other two professions of a wider variety of (nonmedical) treatment approaches.

Further finaings indicate that clinical psychologists and social workers are extremely similar to each other in attitudes toward the treatment modalities, but that psychiatrists are markedly different from these two groups. Psychiatrists are somewhat favorable toward all modalities, while social workers and clinical psychologists are clearly reserved toward necessarily medical treatment approaches. Conversely, psychiatrists, relative to the other two groups, are clearly negative toward apparently nonmedical treatment 
approaches. Psychologists and social workers are more extreme than psychiatrists in the range of their ratings of treatment modalities, al though they do not differ from each other in this regard.

These findings appear to involve differences in professional training, and consequently in autonomous ly accessible or traditionally legitimate treatment methods and in relative professional focus on the "medical model" as a foundation for the provision of mental health care. Thus both theoretical/training and professional self-interest factors may affect professional attitudes toward mental health treatment methods. Possibilities of biases in mental health treatment provision are noted.

Differences between Individual Counseling and Individua 1 Psychotherapy were not sufficiently consistent across all groups and semantic differential dimensions to warrant the assertion that these two modalities constitute separate and distinct treatment methods. 
ATTITUDES OF MENTAL HEALTH PROFESSIONAL GROUPS TOWARD MENTAL HEALTH TREATMENT MODALITIES

AS MEASURED BY THE SEMANTIC DIFFERENTIAL TECHNIQUE

by

GENE STANLEY MORRILL

A thesis submitted in partial fulfillment of the requirements for the degree of

\author{
MASTER OF SCIENCE \\ in \\ PSYCHOLOGY
}

Portland State University

1982 


\section{TO THE OFFICE OF GRADUATE STUDIES AND RESEARCH}

The members of the Committee approve the thesis of Gene Stanley Morrill presented November $2,1982$.

Walter G. Klopfer Chairman

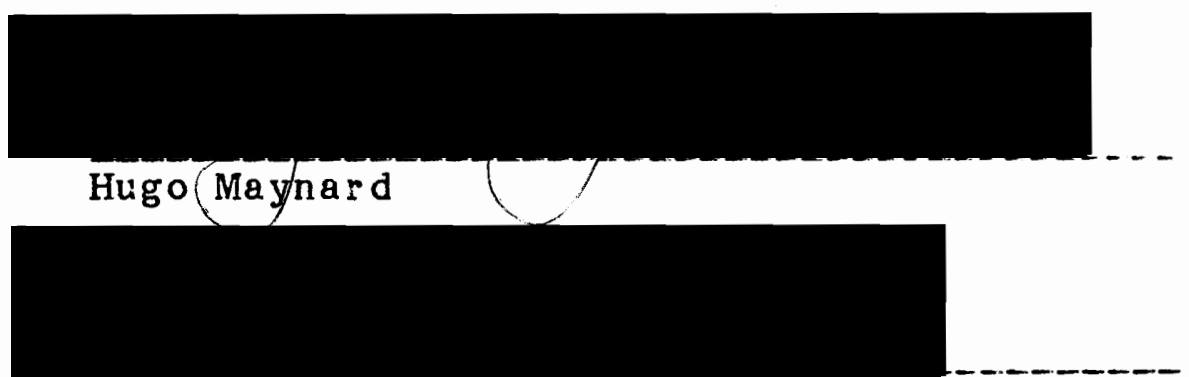

James Paulson

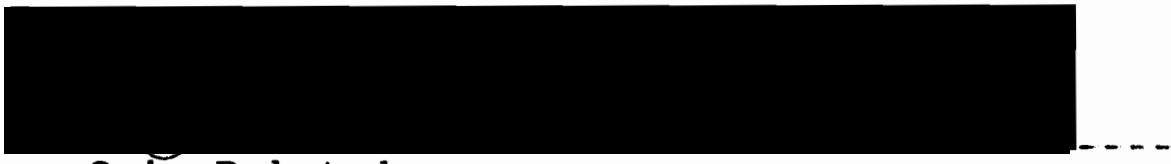

Or in Bolstad

\section{APPROVED:}

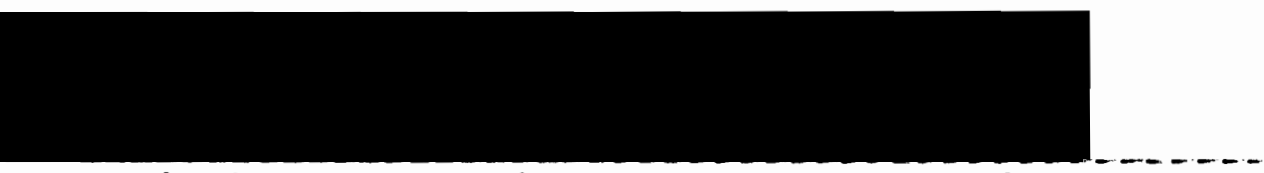

David Wrench, Chairman, Department of Psychology 


\section{ACKNOWLEDGEMENTS}

I wish to thank the members of my thesis committee, Walter Klopfer, James Paulson, Hugo Maynard and Orin Bolstad, for their patient help. Completion of this work would not have been possible without the kind help of Alan Morgenstern, M.D. in gathering data. My special thanks to Linda Neale, Georgia Slack and Ruth Leupold for moral and logistical support during the prolonged process of completing this project. 
TABLE OF CONTENTS

PAGE

ACKNOWLEDGEMENTS . . • . • • . . . . . • . . . . i i i

LIST OF TABLES . . • . . . . . . . . . . . . . . v vi

LIST OF FIGURES . . . . . . . . . . . . . . . . • ix

CHAPTER

I INTRODUCTION • . . . . . . . . . . 1

Problem Statement . . . . . . . . . 1

Literature Review . . . . . . . . . 6

General History of the Problem . . . 6

Individual Counseling Compared to Individual Psychotherapy . . . . 11

Attributes of the Professional Groups

Relevant to Treatment Modality

Preferences . . . . . . . . 15

Hypotheses . . . . . . . . . . 26

The Primacy of Individual Psychotherapy ............ 26

Intergroup Attitude Differences on

Four Treatment Modalities . . . 26

Family Therapy

Group Therapy

Psychiatric Medication

Psychiatric Hospitalization 


\section{CHAPTER}

I I METHODOLOGY . . . . . . . . . . . . 29

Subject Pool and Sampling Procedures . . 29

Measurement Instrument . . . . . . 30

Semantic Differential Technique:

Definition, Dimensionality,

Validity . . . . . . . . . 30

Scale Selection . . . . . . . . 34

Questionnaire Format and Concept

Definitions.... . . . . . 37

Procedures . . . . . . . . . . 39

Data Gathering . . . . . . . 39

Data Analysis . . . . . . . . 40

II I RESULTS . . . . . . . . . . . . . 41

IV DISCUSSION . . . . . . . . . . . 63

Intergroup Differences and Hypotheses . . 63

Individual Counseling Compared to

Individual Psychotherapy . . . . . . 81

Intragroup Differences . . . . . 81

Intergroup Differences . . . . . . 84

Conclusions ........... 87

Summary and Conclusions ....... . 88

REFERENCES . . . . . . . . . . . . . . . 96

APPENDIX . . . . . . . . . . . . . . . 107 


\section{LIST OF TABLES}

TABLE

PAGE

I Attitude Score (Evaluation Dimension)

Means and Standard Deviations for Each

Professional Group for Each Treatment

Modality . . . . . . . . . . .

II Coefficients of Each Modality on the

Significant Standardized Linear

Discriminant Function . . . . . . . . 44

III Results of Classification of Professionals

into Groups on the Bas is of the Linear

Discriminant Function of Their Attitude

scores . . . . . . . . . . . .

IV Between-Group $t$-Tests for Comparisons on

At itude (Eyolugtion Dimension) Score

Means for Each Treatment Modality . . . 50

$V$ Psychologists' Treatment Modality Prefer-

ences: $\quad t$-Tests for Attitude (Evaluation

Dimension) Score Means Within the

Psychologist Group . . . . . . . . 
VI Social Worker's Treatment Modality Preferences: $t$-Tests for Attitude (Eyolughtion Dimension) Score Means Within the Social Worker Group . . . . . . . . . .

VII Psychiatrists 'Treatment Modality Preferences: $t$-Tests for Attitude (Evoluation Dimension) Score Means Within the Psychiatrist Group . . . . . . . . .

VIII Individual Counseling and Individual Psychotherapy Rotency Dimension Score Means and Standard Deviations for Each Professional Group . . . . . . . . .

IX Individual Counseling and Individual

Psychotherapy Actiyity Dimension Score Means and Standard Deviations for Each Professional Group . . . . . . . . . .

$X$ Individual Counseling Compared to Individual

Psychotherapy: t-Tests for Within-Group Comparisons on the Actixity Dimension . . 58

XI $t$-Tests for Between-Group Differences on the Activity Dimension for Individual Counseling and Individual Psychotherapy Modalities.............. 
XII Individual Counseling-Individual Psychotherapy Difference Score Means and Standard Deviations on Eyaluation and Activity Dimensions for Each Professional Group . . . . . . . . . 60 XIII Individual Counseling-Individual Psychotherapy Difference Scores: $t$-Tests for Intergroup Comparisons on the Exaluation, and Activity Dimensions . . . . . . . 61 


\section{LIST OF FIGURES}

F IGURE

PAGE

1. Groups compared on evaluation score means

for each treatment modality .......

2. Histogram plot of all cases on the linear

discriminent function significantly

separating professional groups on the

basis of treatment modality attitude

scores . . . . . . . . . . . . . . 


\section{CHAPTER I}

\section{INTRODUCTION}

\section{PROBLEM STATEMENT}

The task of matching mental health treatment efforts to client/patient needs has long been seen as problematical. The problem is not simply to match each individual's needs to treatment that is helpful, but also to avoid potentially harmful treatment efforts. Miles (1960) has referred to the danger to the patient that is posed by efforts to fit clinical material into "well-ordered categories" even though this may not fit the patient's situation. Furthermore, Goffman (1961) maintains that mental health care may be given with care-provider needs, rather than patient needs, receiving first priority. More recently, Singer (1979) has maintained that the various professionals providing mental health care have a variety of professional/theoretical perspectives which direct and limit the sort of care they provide. That is, she maintains that many mental health professionals have skills limited to one or a few theoretical or operational perspectives and that these mental health care providers often try to force client problems into a form which will fit their professional skills, rather than either expanding their skills to fit multiple and 
diverse client problems or developing other resources for clients.

Such speculations apparently assume that mental health care providers operating from a particular professional/ theoretical perspective will find it in their interest, within their skill range, and/or reflecting their biases to advocate certain kinds of treatment most directly related to their operational perspective, while those care providers operating from a different professional/theoretical viewpoint will, for similar reasons, advocate different kinds of treatment more directly related to their particular professional views. Basically, at issue is whether such treatment provision biases exist in the population of professional mental health care providers.

It is plausible to suppose that if such "force-fitting" biases exist with any consistency, they should be detectable in comparisons between mental health care provider groups whose training and work roles are distinct and relatively homogeneous within occupational groups. Such care provider groups could be supposed to have been trained in relatively mutually distinct professional/theoretical viewpoints and to favor these viewpoints on a group basis. The major mental health care providing professions -- psychiatry, clinical psychology, and social work -- appear to be such groups.

A practical method for gaining direct, valid measures of professional group preference for or avoidance of various 
treatment modalities over a broad client population is not apparent. However, indirect measures of such possible group treatment biases ma be obtained via attitude measurement techniques. It has been maintained that attitudes are valid predictors of behavior (MeCrosky, Larson, and Knapp, 1971; Shotwell, Dingman, and Tarjan, 1960) and that attitudes are "predispositions to respond, but are distinguished from other such states of readiness in that they predispose toward an evaluative response. Thus, attitudes are referred to as 'tendencies of approach or avoidance,' or as 'favorable or unfavorable,' and so on" (Osgood, Suci, and Tannenbaum, 1957, p. 189). Moreover, McCrosky, Larson and Knapp (1971) state that "Attitudes...are our evaluations of people, ideas and things that we observe in the external world" (p. 55), and they quote Fishbein's (1965) definition of attitudes as "learned predispositions to respond to an object or class of objects in a favorable or unfavorable way." Attitude measurement, therefore, appears to be a particularly appropriate and relevant approach to the central problem under consideration here.

The primary focus of this research will be to ascertain whether there are differences between three professional mental health care provider groups -- psychiatrists, psychologists, and social workers -- in their attitudes toward six treatment modalities:

1) Individual Psychotherapy, 2) Individual Counseling,

3) Family Therapy, 
4) Group Therapy, 5) Psychiatric Medication, and 6) Psychiatric Hospitalization.

These six modality designations appear to be sufficiently broad-ranging to encompass treatment responses which may follow from any of several currently widely accepted basic personality/treatment theories (e.g., individual, social and biological) (Monte, 1980). On the other hand, they offer opportunity for some distinctions to be made within as well as between several distinct therapeutic contexts. For instance, within a context of treating groups of people together, there is a possibility of a differentiation between Family Therapy (in which the entire family group at once is seen as the unit of treatment) and Group Therapy (in which individuals or the group process itself may be the focus of treatment). Similarly, treatment provided on an individual basis may be differentiated as Individual Psychotherapy or Individual Counseling. Also, within the context of care associated specifically with medical intervention, a differentiation is possible between care which is necessarily relatively highly structured (Psychiatric Hospitalization) and care which may be provided on a minimally structured outpatient basis (Psychiatric Medication). Thus, some opportunity is presented for considering whether individual, group or medical treatment contexts per se affect professional treatment evaluations or whether finer distinctions within these contexts are meaning 1 . 
It is supposed here that attitudinal measures will reflect biases regarding the different treatment modalities, and that any intergroup differences in such biases may parallel intergroup differences in treatment provision and recommendation patterns.

A secondary, exploratory interest in this study is clarification of the nature of possible differences in certain perceptions about or meanings ascribed to the two treatment modalities Individual Counseling and Individual Psychotherapy by the different professional groups. Such differences regarding these treatment concepts are of particular interest and importance because there appears to be a substantial problem in distinguishing the meanings of these two terms for mental health professionals. Stefflre (1972) has shown in his review and discussion of this problem, that although some authorities maintain that substantial differences exist between these two treatment methods, various efforts to make a clear and final distinction between them have not been successful. Thus it is necessary to try to clarify differences which professionals may understand as characterizing these two treatment modalities.

Such understanding is important for several reasons. First, if these two modalities are regarded differently by the mental health treatment community as a whole, this implies that this community believes these modalities to be substantially different processes, differentially appro- 
priate for different clients for treatment and referral purposes. Therefore, modality differences must be made clear for appropriate treatment to take place. Second, if these treatment concepts in fact do describe different modalities, then the nature of these differences needs to be understood for purposes of training, education, and upgrading of psychological service provision. Third, from a consumer viewpoint, people have a right to know what they pay for and to pay for what they need and want in terms of professional services. Clarifying distinguishing aspects of these two modalities could enhance appropriate choice-making for consumers of mental health services, an important concern for contemporary psychological service providers and their clients (Adams and Orgel, 1975; Mishara and Patterson, 1977 ; Trotter, 1975 ).

\section{LITERATURE REVIEW}

\section{General Histery of the Rroblem}

Differences between mental health care occupational groups which may affect their care provision have been the subject of wide-ranging comment and research. For instance, Kelly (1955) has suggested that communication difficulties among psychologists, psychiatrists, and social workers may follow from "differences in the construct systems employed by psychologists on the one hand and psychiatrists and social workers on the other" (p. 212). Klopfer (1960) has 
also suggested the possibility that theoretical or training differences between these groups may hamper clear intergroup communication.

Empirical verification of supposed differences in theoretical perspective between these groups has been reported. Shearn and Fitzgibbons (1971) asked psychologists, psychiatrists, and social workers to indicate their theoretical orientation from the categories of "psychoanalytic," "other dynamic," "non-dynamic," "eclectic," and "other." Their findings were that psychologists were more likely than the other groups to choose "non-dynamic" and "eclectic" and less likely to choose "psychoanalytic," social workers were more likely than psychologists or psychiatrists to chose "psychoanalytic" and less likely to choose "eclectic" and "other," while psychiatrists were more likely to choose "other" and less likely to choose "non-dynamic" than the other two groups. Interprofessional theoretical differences such as these may underlie the Grayson and Tolman (1950) findings of qualitative differences between clinical psychologists and psychiatrists in both the definitions and the connotations they gave to word-concepts relevant to mental health care.

Such differences in theoretical and semantic orientations could predispose these groups to problems in communication and problems in arriving at mutual understandings regarding mental health care provision. In particular, it seems plausible that such differences may be related to 
findings of differing patient perceptions among mental health occupational groups. This possibility is worth consideration, for the idea that differences in patient perception may affect treatment recommendations has been supported by research unconcerned with intergroup professional differences: McPartland and Richart (1966) have noted that if a clinician perceives a complaint as intrapsychic rather than situational, there is a greater likelihood of recommendation of hospitalization.

Moreover, research focused on interprofessional differences indicates a relationship between profession and patient perception. For instance, Chance, Arnold, and Tyrell (1962) found differences between psychoanalytically oriented psychologists, psychiatrists, and social workers in themes used to describe patients, with social workers and psychiatrists more similar to each other than to psychologists. Also, Goldschmid and Domino (1967) found evidence that such interprofessional patient perception differences may affect treatment recommendations: They found that differences in patient perception exist among a wide range of mental health care occupational groups asked to specify characteristics of patients who would benefit from psychotherapy. Their report suggested that differential perceptions of patients and of the therapeutic process may reflect intergroup training differences and may result in lowering of cooperative functioning in delivering patient care. 
Furthermore, Fontanna, Gessner, and Lorr (1968) have found multiple interprofessional differences relevant to mental health care provision. They found psychiatrists and social workers to differ in theoretical orientation, in perception of patients and pathology, in perception of their role regarding patients, and in treatment recommendations. This report states that psychiatrists are more likely to be theoretically oriented toward a "depth" interpretation of physician-inferred underlying causal processes of pathology, and therefore more likely to regard patients as incompetent to judge these processes or the treatments necessary to change them. In contrast, social workers are reported to be less "depth" oriented and more oriented toward serving the patient, and therefore to be more accepting of the relevance of the patient's ideas and more available to incorporate patient goals into treatment recommendations.

One kind of specific treatment recommendation that has been examined with respect to intergroup care-provider differences is recommendation for hospital discharge. Lorei (1970) found some evidence of interprofessional differences regarding the relative importance of different consequences of release of patients from psychiatric hospitalization. In this study, social workers were found to be less concerned about post-release indigency than psychologists and psychiatrists, and less concerned about post-release idleness than psychiatrists. Weinstein (1964) also found indications of 
some differences between psychologists, social workers, and psychiatrists in the factors they used to evaluate patients' readiness for psychiatric hospital discharge, with psychiatrists emphasizing a patient's emotional and perceptual state more than the other two groups.

Another mental health treatment recommendation focus which has been examined with respect to professional intergroup differences is choice of treatment for children. Weissman (1969a, 1969b, 1975) has investigated the possibility that psychologists, social workers, and psychiatrists show professional group differences in criteria they would ideally use in selecting treatment modalities (or no treatment) for children with specific diagnoses. His reason for developing this research was his concern "that difficulties attendant upon arriving at clinically appropriate dispositions may be largely attributable to discrepancies in perceptions that reflect the varying theoretical vantage points of the three professions" $(1969 \mathrm{a}, \mathrm{p} .75)$. The initial findings suggested that "patients are in fact viewed differently by different mental health workers and these differences have significant implications for patient management" (1969a, p. 9).

Further research (Weissman, 1969b) indicated that social workers are more concerned than the other two groups with social and environmental factors as ideal criteria for treatment choice (individual or group therapy, or no treat- 
ment), while psychologists were more concerned with individual attributes such as symptoms, intellectual function, and motivation, with psychiatrists suggested to be more like psychologists than like social workers. Among Weissman's preliminary conclusions is stated, "Differences in training and orientation are clearly reflected in the cues that each profession selectively perceives and differentially evaluates in the patient" (1969b, p. 15).

Despite the work cited above, the issue of whether consistent interprofessional differences exist in patient perception, evaluation, or treatment recommendation is not finally resolved. In Weissman's latest (1975) research regarding this question, using a broad national sample and modified approach (closed- rather than open-ended questionnaires), no differences were found in the criteria the three professional groups would ideally use in deciding which treatment (individual, group, conjoint family therapy, or no treatment) would be most appropriate for children with a specified diagnosis. However, the low response rate (approximately 39\%) found in this study leaves much room for debate of the finding of no differences.

\section{Individual Counseling Compared te Individual Esychotherapy}

The distinction between the terms "counseling" and "psychotherapy" is an unresolved issue which has been subject to intermittant debate in the literature for over 
twenty-five years. In his review of the counseling literature, Shaw (1957) indicates that mental illness may be the province of the clinical psychologist and creative health that of the counseling psychologist. However, beyond that he will not go, confining his attention "to theoretical and conceptual trends without any presumption that these trends apply in any exclusive way to counseling psychology in contradistinction to clinical psychology or psychotherapy" (p. 357 ).

In contrast, Tyler's (1958) counseling review immediately maintains that "counseling,' viewed as a process, is a term that parallels 'psychotherapy'" (p. 375). She maintains that counseling is ego-centered and focuses on a specific type of problem (e.g., personal development, identity development, work, values, role conflicts), while psychotherapy focuses on personality change and organization. According to Tyler, "counseling aims at acceptance of assets and limitations rather than at fundamental personality change. Its function is to strengthen the ego rather than to reduce pressures from the id" (p. 376). However, in a review of the counseling literature immediately subsequent to Tyler's, Berdie (1959) dismisses this distinction, maintaining, "The definition of counseling and its distinction from other related activities still await empirical investigation" (p. 345). Lacking an empirical basis for differentiation, he used such terms as "therapy" and "counseling" 
interchangeably, a practice followed by other major contributors to the literature (e.g., Carkhuff and Berenson, 1967; Truax and Carkhuff, 1967; Whiteley et ale, 1975). This problem of ambiguity in terminology and meaning is emphasized in Patterson's (1966) review, another examination of counseling which concedes no essential difference between it and psychotherapy.

Brayfield's (1963) review of the literature in counseling psychology yields noteworthy points: Paterson and Lofquist (1960) found that there were few substantive differences in the requirements of American Psychological Association approved doctoral programs in counseling and clinical psychology, but Granger (1959) found that counseling psychologists were ranked lowest in prestige of selected doctoral specialties in psychology. Low status may be a function of the confusion surrounding the term "counselingn as a profession and process, for Pepinsky and Meara (1973) note in their review, "...counseling is the label attached to a conglomerate of activities that otherwise have little in common with each other. To identify counseling further as a helping activity is simply to align it with a host of events with other labels (e.g., therapy, social service, education, the ministry, the law, etc.)" (p. 197).

The literature ranges from elaborate attempts to develop theories and models with which to differentiate counseling from psychotherapy (e.g., Vance and Volsky, 1962) to 
closely reasoned and adamant counter-arguments denying any differences between the two (e.g., Patterson, 1967). Stefflre (1972) offers some resolution in his review of literature concerned with distinctions between counseling and psychotherapy. He draws the following conclusions regarding differences in method between the two: "...counseling is characterized by shorter duration of treatments, less frequent visits, more use of psychological examination [formalized interview test procedures rather than the taking of an extensive historyl, more concern with...present daily problems, more focus on conscious activities, more advice giving, more emphasis on the reality situation, more cognition and less emotional intensity, more focus on achieving clarity and less allowance of ambiguity" (p. 22).

Although the issues are certainly not formalized and clear, it seems that the overall implication of the literature tends to be: Counseling is easier and quicker to achieve than psychotherapy, it does not have as basic, profound, or important an impact as psychotherapy, it is suitable for "normal" or less difficult problems rather than the more severe emotional disturbance or psychopathology appropriate for psychotherapy, and, therefore, counseling is not as positively valued as psychotherapy. 
Attributes of the Professional Groups Releyent to Treatment Medality Preferences

Henry, Sims, and Spray (1971, 1973) carried out an extensive, multifaceted study of more than 4000 mental health professionals (in effect, the entire universe of psychiatrists, psychoanalysts, clinical psychologists, and psychiatric social workers in New York, Los Angeles and Chicago). Many of their findings and conclusions are quite relevant here, and will be examined in some detail.

They note that autonomy in performance of professional function is of central importance in all professions, and that in mental health this results in individual, one-to-one psychotherapy being strongly emphasized across all the professional specialties. This is especially so for psychiatrists: "Medical schools, medical internships, and psychiatric residencies are all designed to convey the notion that the private office is the ideal setting for professional practice. Thus, in lecturing to resident doctors, members of hospital staffs frequently place the greatest emphas is on one-to-one psychotherapy" (p. 11).

This quest for and training toward professional autonomy also exists in clinical psychology: "The professional socialization of clinical psychologists is designed to inculcate many of the same expectations regarding the unfettered applications of professional expertise that psychiatrists acquire in medical training programs organized around the doctor-patient relationship" (p. 12). A similar 
focus developed for social work as it shifted from a "reform" to a "professionalism" orientation through the broad adoptation of a psychodynamic treatment perspective as a basic professional viewpoint: "...it is clear that psychiatric social workers are trained to expect and are effectively demanding autonomy in the performance of diagnostic, counseling, and psychotherapeutic functions in the mental health field" (p. 13).

The conclusion is that for all these mental health professions, individual psychotherapy is the treatment of choice: "...the professional image, which is both reflected and reinforced in all...the professional training programs, puts individual psychotherapy at the core of the profession... individual psychotherapy not only serves as the focal point for professional training programs, but also functions as the symbolic core of professional identity in the mental health field" (pp. 13-14). Indeed, fifty-seven per cent of all respondents in this study designated their major therapeutic orientation as one which is usually carried out in a process labelled as individual psychotherapy, e.g. "psychoanalytic."

More specifically, the findings of this study were that twice as many psychiatrists as clinical psychologists or social workers make the provision of individual psychotherapy their main professional role; social workers and clinical psychologists were found to be equal in this re- 
spect. It seems clear that a large portion of all groups considers their principle professional role to be that of "individual psychotherapist," with psychiatrists outstanding in this respect:

The...medical mental health care providers are much more narrowly specialized in the range of roles they perform than is true of either of the nonmedical groups.... [T]he differential participation in the performance of one-to-one psychotherapy, in one form or another, distinguishes the medical from the non-medical practitioners. Specifically, when the roles of psychoanalyst and individual psychotherapist are combined they account for an absolute majority of...psychiatrists. The corresponding figure for the two nonmedical professions is approximately one-third of the membership of each group. (Henry, sims, and Spray, 1973, p. 51 )

This finding is supported by other writers' observations of the emphasis given the individual psychotherapy orientation, especially in psychiatry (Armor and Klerman, 1968 ; Casariego and Greden, 1978 ; Charatan and Rosenblatt, 1969; Greden and Casariego, 1975). Similarly, in clinical psychology, there has been an emphasis on autonomy in professiona 1 treatment provision (Rie, 1977) and documentation of the great extent to which individual psychotherapy is practiced by these clinicians (Garfield and Kurtz, 1974; Wellner, 1977). The social work literature also supports the legitimate, esteemed place of individual psychotherapy among the treatment approaches used in this profession (Boehm, 1960; Meyer, 1971; Sackheim, 1974; Whit taker, 1974). 
A related finding is that of House, Miller and Schlacter (1978). Here, although social workers saw themselves as especially skilled in group and family therapy and dealing with larger community system problems, while psychiatrists saw themselves as being uniquely skilled at treating emotional problems with medication, and psychologists perceived their strength as psychological testing, all groups spent the greatest amount of their direct service time in the conduct of individual psychotherapy.

Henry, Sims, and Spray (1973) also note that psychotherapists with a medical background hold "professional designation" as the most important criteria for differentiating psychotherapists, while clinical psychologists and social workers are more interested in the "functions and activities" of the therapists. The authors interpret this difference as a result of the acceptance by the medical psychotherapists of the official position of the American Medical Association, American Psychiatric Association, and American Psychoanalytic Association (1954) that "psychotherapy is a form of medical treatment and does not form the basis of a separate profession" (p. 385). A central implication of this statement, that training received in medical school is the basic foundation for the treatment of mental illness, appears to have been accepted by a significant proportion of the psychiatrists in this study. The belief that being a physician is fundamentally necessary to the 
ability to practice psychotherapy effectively is found in other sources (Mittel, 1978; Monroe, 1960; Pinney, Jr., $1970)$.

The Henry, Sims, and Spray (1973) study notes that psychiatrists believe that they see an unusually wide range of patients when compared with other professional groups, an apparent self-validation of the primacy and usefulness of medical training in providing mental health care. However, this study found that when the professionals report the diagnoses of persons treated, psychiatrists are not unique in terms of the diagnostic range of patients treated. They found that psychiatrists do treat a larger proportion of psychotic persons than the other professions, while clinical psychologists and social workers see proportionately more relatively healthy and psychoneurotic patients. These differences do appear to be due to the medical training of psychiatrists:

The major distinction in types of patients treated is between the medically and nonmedically trained psychotherapists, rather than between psychiatrists and the other professional groups.... The differences between the medical-organic and the psychological approaches to the treatment of mental illness produce the professional division of labor.... [I]n discussing therapeutic techniques, $46 \%$ of the entire interview sample noted that the therapeutic approach of psychiatrists emphasized the fact that they are physicians; hence they can and do use techniques such as medication and electroshock therapy to treat severely disturbed patients. Approximately one-half of the [sample] singled out the medically based techniques as characteristic of psychiatrists.... [T] on their medical background as a basis for treating 
mental illness serves to distinguish them from nonmedical therapists.... (Henry, Sims, and Spray, 1973, p. 28 )

Henry, Sims, and Spray (1971, 1973) also draw contrasts between psychiatrists, clinical psychologists and social workers in terms of the effect of training background on certainmotivational perspectives. That is, the clinical psychologists seem to operate within a system of causation per the scientific method, while psychiatrists and social workers are more pragmatic:

...[T]he dominant ethos of the training programs of clinical psychologists revolves around the belief that the ability to modify human behavior is primarily dependent upon the ability to explain it in terms of cause and effect relationships.... [T]his...contrasts sharply with psychiatry and social work.... Both [these] professions are more pragmatical ly concerned with the how rather than the why. Psychiatry is focused on treatment per se, on the alleviation of symptoms; social work is focused on caring for the socially handicapped and on creating social reform. (1973, p. 48)

These differences are attributed to the academically oriented training of clinical psychologists in research methods culminating in a dissertation. Clinical psychology thus focuses on a perspective involving scientific methodology and conceptualization, a distinctive feature when compared to the other groups. This rational scientific focus as a basis for mental health care provision among clinical psychologists has been described and emphasized by others (Derner, 1960; Hathaway, 1958; Orne, 1975; Riess, 1960; 
Wellner, 1977). Henry, Sims, and Spray (1973) see this orientation as having an effect of broadening the scope of professional roles (and, one may infer, treatment modalities) acceptable to this professional group:

The fact that the training of clinical psychologists focuses on a general perspective rather than a particular technique or set of problems probably also accounts for the fact that, as a group, psychologists are the most uniformly distributed among...professional roles. (p. 50)

Another area considered by Henry, Sims, and Spray (1973) is of particular interest here. That is, the relative proportions of the three professions practicing group therapy and individual psychotherapy. The authors regard any such role choice as a function of professional training and identity. With regard to differentiating the groups on the basis of individual versus group treatment orientation due to distinctive perspectives, the authors emphasize the views of a study informant:

...[P]sychiatric social workers tend to deal in social interaction more than with the individual. Their main focus is not on the individual's inner problems. Psychiatrists, on the other hand, often hospitalize patients and use drug therapy and shock treatment. Even in psychotherapy, psychiatrists tend to be more oriented to treatment of the individual's inner processes. Clinical psychologists are somewhere in between these two approaches in that they are oriented to the treatment of the individual's inner processes, but they are also stepping out more into group therapy, community psychiatry, and similar approaches. (p. 19) 
Here, group therapy was defined as focusing on small group interaction, including marriage and family therapy, and "strongly emphasizes the role of social and interpersonal factors in the treatment of mental illness. The emphasis on family therapy reflects the view that family interaction is an important agent in the etiology of mental illness" (p. 47). Their finding was that approximately three times as many social workers as psychiatrists spent the largest proportion of their time doing group therapy, with one-third more psychologists than psychiatrists so commiting their time. In contrast, only three-fifths as many psychologists and social workers as psychiatrists spent the major portion of their time doing individual psychotherapy .

These findings are supported by the comments of other investigators. Nacman (1977) notes the increasing involvement of psychiatric social workers in group therapy and family therapy in hospital-related treatment. Douglas (1979) states that a wide variety of problems and goals have been addressed historically by social workers using group methods. Similarly, Turner (1978) asserts, "Within the social work literature, there are few situations and personality types that have not been suggested as being amicable to group treatment. The professional literature contains articles that support the use of groups for virtually every presenting situation and factor" (p. 126). Napier and 
Whitaker (1978) maintain that social work training, with its emphasis on a social system focus, is the most appropriate training for family therapy. Moreover, over twenty years ago Lidz, Hotchkiss, and Greenblatt (1957) found the role of the social worker to be the family oriented professional, "trained to understand family problems" (p. 543).

The intermediate ranking of clinical psychologists between social workers and psychiatrists in terms of focus on group (and family) therapy appears to be consistent with the findings of Garfield and Kurtz (1974) that the provision of group psychotherapy accounts for a small but significant amount (about 5\%) of the professional time of all clinical psychologists. This figure includes exclusively academic professionals, so one may suppose that the percentage would be higher for those psychologists active in clinical practice. This intermediate ranking of clinical psychologists is also consistent with Wellner's (1977) finding that onethird of the clinical psychologists in private practice offer group therapy. Clinical psychologists may thus be seen as more oriented toward group process than the primarily individually oriented psychiatrists, but less so than social workers. Certainly, as Mullan and Rosenbaum (1962) have described, psychologists and social workers have historically both been involved in developing the provision of group psychotherapy. 
Overall, these findings are generally consistent with the comments of a number of other writers on mental health professional roles and interprofessional differences. Ursano and Dressler (1977) state that professional mental health training affects clinician attitudes toward the use of a particular treatment modality, and Brody (1960) states "...the nature of the psychotherapy practices by any individual will be a function of his identification with his profession as well as his teachers and supervisors in therapy $^{n}(p, 88)$.

One major basic study dealing with such propositions was done by stauss et ale (1964). They investigated the relationship between professional affiliation and three etiological/treatment ideologies: the Rsychotherapeutic (psychological-trauma-impaired intrapsychic systems cause emotional disorders -- treat by emphasizing the therapistpatient relationship), the sematetherapeutic (neurological or biological dysfunctions cause emotional disorders -treat with chemical or direct physical means), and the societheraneutic (social and interpersonal stresses, especially family interaction, cause emotional disorders -- treat by providing a consistent positive interpersonal environment). They concluded that professional affiliation strongly influences the professional's position with respect to these etiology/treatment orientations. They found that psychiatrists chiefly supported either the psychotherapeutic 
or somatotherapeutic position. They postulated and found that the sociotherapeutic view was most favorably regarded by social workers, with psychiatrists least favorable and psychologists intermediate. Also, they found the psychotherapeutic self-designation the most frequent choice in all groups. Using training as a basis for ordering professions, they predicted that psychiatrists would be most somatotherapeutically oriented, followed by psychologists and social workers. The psychiatrists ranked as predicted, with psychologists and social workers not significantly different from each other, and both less somatotherapeutic in orientation than psychiatrists. They attributed the finding of no social worker-psychologist differences to aberrations in the data.

Other researchers have elaborated this picture. Morrison and Nevid (1976) found psychologists and social workers significantly more accepting than psychiatrists of a "psychosocial" position regarding treating mental illness; the psychosocial position is generally opposite to the medical/somatic mental illness model and emphasizes the place of social systems variables in the causality of mental/ emotional disorders. This finding is consistent with those of Myers and Rosen (1966) and Coryell and Wetzel (1978) that psychiatrists may emphasize individual psychotherapy and drugs in their treatment orientations. A study by Antonio and Innes (1978) is conceptually related to these. They 
found that the professional background of the clinician will influence the attribution of cause and therefore the type of treatment to be recommended: Psychiatrists were found to be more likely to make personal attributions than psychologists, and thus more likely to recommend mental hospital rather than community treatment.

The findings described above are a sampling of the literature which supports the plausibility of the following hypotheses.

\section{HYPOTHESES}

The Primacy of Individual Esychetherapy

The concept Individual psychotherapy has had a primary place historically in psychotherapeutic treatment and in therapy training programs. It appears that the concept Individual Psychotherapy has frequently been associated with expectations of extensive treatment efforts and large investments of time and resources, resulting in relatively substantial and permanent psychological change. Such historically favorable regard toward this concept led to the hypothesis that Individual Psychotherapy would be the treatment modality associated with the most positive attitudes for all the professional groups.

Intergroup Attitude Differences on Eour Tregtment Modelities

Eamily Therapy. It was hypothesized that social workers, because of their training focus on interpersonal, 
social-ecological and familial processes in delivering mental health care, would have a more positive attitude toward Family Therapy than psychiatrists, whose medical training has focused them more on individual processes. Clinical psychologists are likely to have some overlap with social workers in exposure to or training in interpersonal developmental, group dynamic and social-psychological processes, and to ideas of causality involving supraindividual constructs. Thus, psychologists were hypothesized to be intermediate on the Family Therapy modality.

Group Therapy. It was hypothesized that social workers would have a more positive attitude toward Group Therapy than psychiatrists, with psychologists intermediate, for the same reasons cited directly above.

Rsychiotric Medication. It was hypothesized that psychiatrists, because of their medical training, would have a more positive attitude toward Psychiatric Medication as a treatment modality than social workers, whose training seems least likely to orient them toward individual disease processes and medical treatment as appropriate perspectives for psychotherapeutic efforts. However, psychologists, who are likely to have had some training in such areas as diagnostic psychometrics, individual developmental/genetic differences and physiological psychology, would be more receptive than social workers to ideas of causality consistent with individual, biological, diagnostic treatment approaches such as 
28

characterize medical care. For these reasons, it was hypothesized that psychologists would be found intermediate in attitude toward the Psychiatric Medication treatment modality.

Psychiatric Hospitalization. It was hypothesized that psychiatrists would have a more positive attitude toward Psychiatric Hospitalization as a treatment modality than social workers, with psychologists intermediate, for the same reasons explained directly above. 


\section{CHAPTER II}

\section{METHODOLOGY}

\section{SUBJECT POOL AND SAMPLING PROCEDURES}

Forty subjects from each of the three major professional mental health care provider groups -- psychiatrists, clinical psychologists, and social workers -- were sent the attitudinal questionnaire described below. Psychiatrist subjects were randomly chosen from the Directory of Begistered Licensees. Beard of Medical Examiners of the State of oregon (1979 edition). The same random procedure was followed in choosing psychologist subjects from the listing of current Ph.D.-level psychologists licensed for clinical practice as enumerated in the oregen Psychological Association Membership Directory (1979-1980 edition). Social worker subjects were similarly chosen from the State of Oregon Registry of Clinical Sociel Workers (1979 edition), a voluntary register of social workers in private practice who meet certain standards defined legally by the State of Oregon. Responses were included only from professionals providing or directly supervising the provision of clinical mental health care at the time of data collection.

A geographical limitation confining subject sampling to a relatively small area within the state of Oregon was the 
only exception to true random sampling from the above listings. All subjects were chosen from the tri-county area encompassing metropolitan Portland, Oregon: Multnomah, Washington, and Clackamas Counties. This limitation was maintained so that follow-up contact for questionnaire return could be accomplished with relative ease. This sample constituted approximately $25 \%$ of the state-licensed psychiatrists, $20 \%$ of the state-registered clinical social workers, and $20 \%$ of the state-licensed clinical psychologists in this area, as determined from publicly available professional list ings.

\section{MEASUREMENT INSTRUMENT}

Sementic Differential Technique: Definition. Dimensienality, Validity

Semantic differentiation is basically the process of differentiating stimuli by rating them on bipoiar (opposite in meaning) adjective scales, such as geed=bad or hot=cold. More than twenty years of diverse empirical research findings have supported the idea that the connotative/affective (and to some extent denotative) meaning of any concept (or, possibly, any distinct stimulus) can be designated by semantic differentiation along orthogonal dimensions of eygluation, gotency, and ectiyity (Osgood, Suci and Tannenbaum, 1957). As Osgood explains, "Despite deliberate and independent variations in the rules for sampiing scales and concepts and in the kinds of subjects 
used, three dominant, orthogonal factors have kept reappearing: an 'evaluative' factor (represented by scales like good=bad, kind=cruel, and honest=dishonest), a 'potency' factor (represented by scales like strong=weak, hard=soft, and heayy=light) and an 'activity' factor (represented by scales like active=Dassiye, fast=slow, and hot= cold). What this means is that there are at least three 'directions' in the semantic space that are regions of relatively high density, in the sense of containing many highly correlated scales representing similar modes of qual ifying. Evaluation, potency, and activity (EPA) appear to be the most salient modes of qualifying experience" (Osgood, 1965, p. 110). Many other researchers have verified these ideas and demonstrated their importance, usefulness and broad applicability (Snider and Osgood, 1969). As Heise notes, this formulation of a basic generalized structure of meaning, or a derivative or limited modification of it, seems to be virtually universal in human groups: "There is probably no social or psychological principle that has received such resounding cross-group and cross-cultural verification as the EPA structure of SD ratings" (1969, p. 427$)$.

Of particular interest is the evalugtion dimension of the semantic differential. Typically, it accounts for over twice the variance in scales as the potency and activity dimensions combined, and it is usually the primary (first) 
factor to appear in semantic differential research factor analyses (Osgood, Suci, and Tannenbaum, 1957). The predominance of this meaning dimension is said to reflect the predominance of evaluative, or attitudinal, judgments in the assignment of meaning to concepts. In fact, it has been stated that "The meaning of a concept is its location in a space defined by some number of factors or dimensions, and attitude toward a concept is its projection onto one of these dimensions defined as "evaluative'" (Osgood and Tannenbaum, 1955 , p. 42).

Focusing on the evaluation dimension of the semantic differential technique has been identified as a clearly useful approach to attitude measurement. For instance, Kerlinger points out the usefulness of exelulation dimension semantic differential scales in attitude research and states that "...SD factor scores are psychometrically sound and substantially interpretable... Eveluation factor scores - sums or means of E adjective-pair scales -- are the most useful for many behavior research studies" (1967, p. 577). Osgood and his colleagues maintain that "...the evaluative factor of the semantic differential is an index of attitude.... [I]t does...provide an index to the location of the attitude object along a general eveluative continuum.... It is apparent that the semantic differential may be used as a generalized attitude scale" (Osgood, Suci, and Tannenbaum, $1957)$. 
In support of these views, several studies which specifically validate the use of the exaluatien dimension semantic differential scales as attitude measurement instruments have been reported (Osgood, Suci, and Tannenbaum, 1957). Further evidence for the validity and usefulness of this approach is the fact that many studies in qualitatively varied contexts have successfully used exglugtion dimension semantic differential scales in attitude measurement (e.g., Block, 1957; Staats and Staats, 1958; Tannenbaum, 1966). Finally, the semantic differential approach has been used to measure the attitudes of mental health care providers toward mental health treatment methods (Baker and Schulberg, 1967; Kurtz and Kaplan, 1968; Stone, Stein, and Green, 1971).

A problem which must be dealt with when using the semantic differential technique is concept-scale interaction. To some extent, specific scales may "rotate" and measure meaning on (load heavily on) factorial meaning dimensions different than those they were chosen to indicate, depending on the concept being judged. Here, possibilities of this effect were minimized in two ways. First, the class of concepts judged is quite narrowly limited (psychotherapeutic treatment modalities), and according to War and Knapper (1968) this limits the likelihood that the different scales will rotate toward different dimensions, as they claim would be more likely to occur if e wide variety of concepts was measured. 
Second, possibilities of picking up large effects due to concept-scale interaction were minimized because the evaluation dimension was measured using an average score of 12 closely related scales which have been found rationally and empirically to represent the exolugtion, or attitudinal, dimension of meaning most broady. This relatively broad multiscale attitude measurement approach minimized the possible effects on an overall group attitude score, or rating scale mean attitude measure, due to any (undetectable) rotation of any single scale away from the eyoluation dimension of meaning measurement. This was done, even though methodological inquiry indicates that three or four scales may be ordinarily sufficient to represent a factorial meaning dimension (Heise, 1969; Kerlinger, 1967), and some researchers have used only two scales for such representation (Jenkins, Russell, and Suci, 1958), or even one (staats and Staats, 1958).

\section{Scale Selection}

Well defined requisites for scale selection for semantic differentiation have been developed through theoretical and research work. These requirements are basically that "scales must be representative of attitudes in the domain to be explored; they must be well defined for the population of interest; they must be appropriate to the concept in the domain; and they must be polar opposites" (Maguire, 1973, 
p. 297).

Scales in use here have been derived from an analysis by Osgood and his colleagues which was an effort to obtain a "logically exhaustive" sampling of semantic dimensions. In this analys is the evaluation dimension (factor) scales were selected out by a factor analysis of 76 representative polar opposite adjective scales developed through a methodical and complete examination of Regetis Thesaurus (1941 edition) (Osgood, Suci, and Tannenbaum, 1957). These polar opposite scales, broadly representative of all those which could be constructed using the English language, were factored over 20 widely varied concepts from five distinct concept classes (person concepts, physical objects, abstract concepts, event concepts, and institutions). Thus, the scales and concepts used to develop factorial dimensions of meaning were deliberately chosen to maximize variability and the possibility of detecting additional or alternative dimensions of meaning (aside from eyeluation, potency, and actiyity, previously established), and to detect changes in the order of the dimensions in terms of percentage of scale variance accounted for. It can be seen, then, that the factorial meaning dimensions derived from this procedure, and the loadings and clusterings of the adjective-pair scales found in this analysis, were developed from the most logically consistent approach possible to finding a complete and detailed listing of factorial meaning dimensions. 
A "square root" factorization of the data found evelue= tien, Rotency, and ectivity again to be dimensions of meaning accounting for the most scale variance, with the exaluetion (attitudinal) dimensions again accounting for more common variance than any other factor (Osgood, Suci, and Tannenbaum, 1957). The twelve scales to be used as an attitude measure in this study were chosen from those loading heavily on the exaluation dimension of this factor analysis.

Scales selected were, first, those most purely loading on this evaluation factor: geod=bad, eptimistic= pessimistic, positiyenegotive, and complete=incomplete. Secondly, scales were selected which may represent subdivisions of the exeluation dimension, or "modes" of evaluation, since they have noticeable subsidiary loadings on other possible dimensions. These possible eveluation modes, as reported by Osgood and his colleagues, and the scales selected to represent them in this study are: "meek goodness," altruistic=egotistic, kind=eruel; "dynamic goodness," successful=unsuccessful, progressive=regressive; "dependable goodness," reputable=disreputable, wise=foelish; and "hedonistic goodness," Rleasurable=painful, meaningful= meaningless (Jenkins, Russel, and Suci, 1958; Osgood, Suci, and Tannenbaum, 1957). The above scale selection also reflects the requirement that scales be appropriate (relevant) for the concepts to be differentiated, as determined by 
investigator judgment of the hypotheses to be investigated and areas to be explored (Maguire, 1973; Osgood, Suci, and Tannenbaum, 1957).

Additionally, eight other scales derived from this same factor analysis were included as measures of the potency and gctivity dimensions. Measures on these dimensions were used to explore for Individual Counseling-Individual Psychotherapy differences in addition to eveluation dimension differences. The scales measuring the petency dimension were: strong=weak, severe=lenient, constroined-free, and tenacious=yielding. For the activity dimension, the scales were: active=pessive, fast=slow, excitable=calm, and complex $=$ simple.

Questionnaire Eormat and Cencept Definitions

The questionnaire and instructions (see Appendix) were in a format studied and recommended by Osgood, Suci, and Tannenbaum (1957). Each questionnaire page contained all twenty bipolar adjective scales and one concept printed at the top, so that each concept was rated on a separate page on all scales. Scales were alternated in polarity to prevent formation of a position set. The order and polar orientation of all scales were the same for all concepts on each questionnaire (i.e., for each subject).

On each bipolar scale, seven equally graduated possible response positions were presented for a single response 
choice. The middle position (a 4 on the 1 to 1 rating system used) was described as a completely neutral choice. Subjects indicated their response by simply placing a mark in the scale position appropriate to their reaction to the concept being rated. They did not make any overt numerical ratings. Numerical values were later assigned by the experimenter on the following basis: evgluation dimension, 1 = most positive, $I$ = least positive; Rotency dimension, $1=\operatorname{most}$ potent, $\quad I=$ least potent; activity dimension, $1=$ most active, $I$ = least active.

The instructions for completing the semantic differential questionnaire referred each subject to a single set of concept definitions (see Appendix), which provided a consistent reference point for all modalities being evaluated. Each treatment modality was given a brief definition which was to be used by all subjects in filling out the semantic differential forms. For all treatment methods, it was assumed that these orienting but relatively neutral and general definitions would stimulate responses providing information indicative of both intergroup and intragroup differences in attitudes toward the modalities.

For the primary purposes of this study, possible ambiguity regarding the meanings of the treatment modality concepts Individual Counseling and Individual Psychotherapy could have posed a problem. That is, if these concepts had been totally undefined here, subjects might have responded 
to widely diverse ideas about what these terms referred to, confounding attitude measurement conclusions. On the other hand, if these concepts were too narrowly defined, then possibilities of achieving the secondary purpose of this study, exploring the possibility of the existence of meaning differences between the concepts Individual Counseling and Individual Psychotherapy, would have been limited. Furthermore, since it is clear that distinguishing these processes has been a long-standing problem, arbitrarily forcing a priori distinctions via overly restrictive concept definitions could have limited information gathered, distorting results. In order to pursue both the primary and secondary foci of this study, a balance had to be achieved between information loss and ambiguity of information gained. Therefore, the terms Individual Counseling and Individual Psychotherapy were purposefully less restrictively defined than the other four treatment modality terms. (See Appendix.)

\section{PROCEDURES}

\section{Data Gathering}

Each of the 120 potential respondents was mailed a sixpage semantic differential questionnaire, one page of instructions for filling out the questionnaire, one page of concept definitions, a cover letter briefly explaining the study, and a stamped, addressed envelope for questionnaire 
return. Approximately one month after the initial mailing, subjects who had not returned their questionnaires were sent reminders. If no response followed within one week, a follow-up telephone call was made, with another questionnaire packet mailing as appropriate. If these contacts were not productive, further telephone and mail solicitations followed. Unlocatable potential subjects were replaced through the random sampling procedure previously described. An effort was made to achieve an $80 \%$ response rate (32 questionnaires per group). The response rates finally achieved were: psychiatrists, 80\% (32/40); psychologists, $80 \%$ $(32 / 40)$; social workers $85 \%(34 / 40)$.

\section{Data Analysis}

The dependent variable score analyzed for hypothes is testing was for each subject, the sum of the ratings on the twelve scales (described previously) which were chosen to represent the semantic differential technique attitudinal measure (i.e., the evaluation dimension). Similarly, for exploration of Individual Counseling and Individual Psychotherapy differences on the other two dimensions, for each subject the sum of the ratings on the four scales associated with either dimension was the subject's petency or activity dimension score. Dependent variable scores were analyzed using statistics as described in the Results section. 


\section{CHAPTER II I}

\section{RESULTS}

Figure 1 indicates that the groups differ in their profiles of mean attitude scores on the treatment modalities. Table 1 provides means and standard deviations of attitude scores of each professional group on each treatment modality.

The extent of these differences was examined using a multivariate analysis of variance (Tatsuoka, 1971) to determine if the profiles of responses to the modalities differed significantly from group to group. All the multivariate analyses reported in this section were carried out using the "Discriminant Analysis" program found in Statistical Package for the Secial Sciences (Nie et ale, 1975). This analys is confirmed that the groups differ at a statistically significant level (Wi $\mathrm{ks}^{\prime}$ Lambda $=0.54, E(12,180)=5.49, \mathrm{R}<$ $0.0001)$.

Figure 1 suggests that the overall group differences are the result of the difference of the psychiatrist group from the other two groups, with the psychologist and social worker groups not differing markedly from each other. This was confirmed statistically: The E statistic corresponding to Hotellings' $T^{2}$ for psychiatrists compared to psychol- 


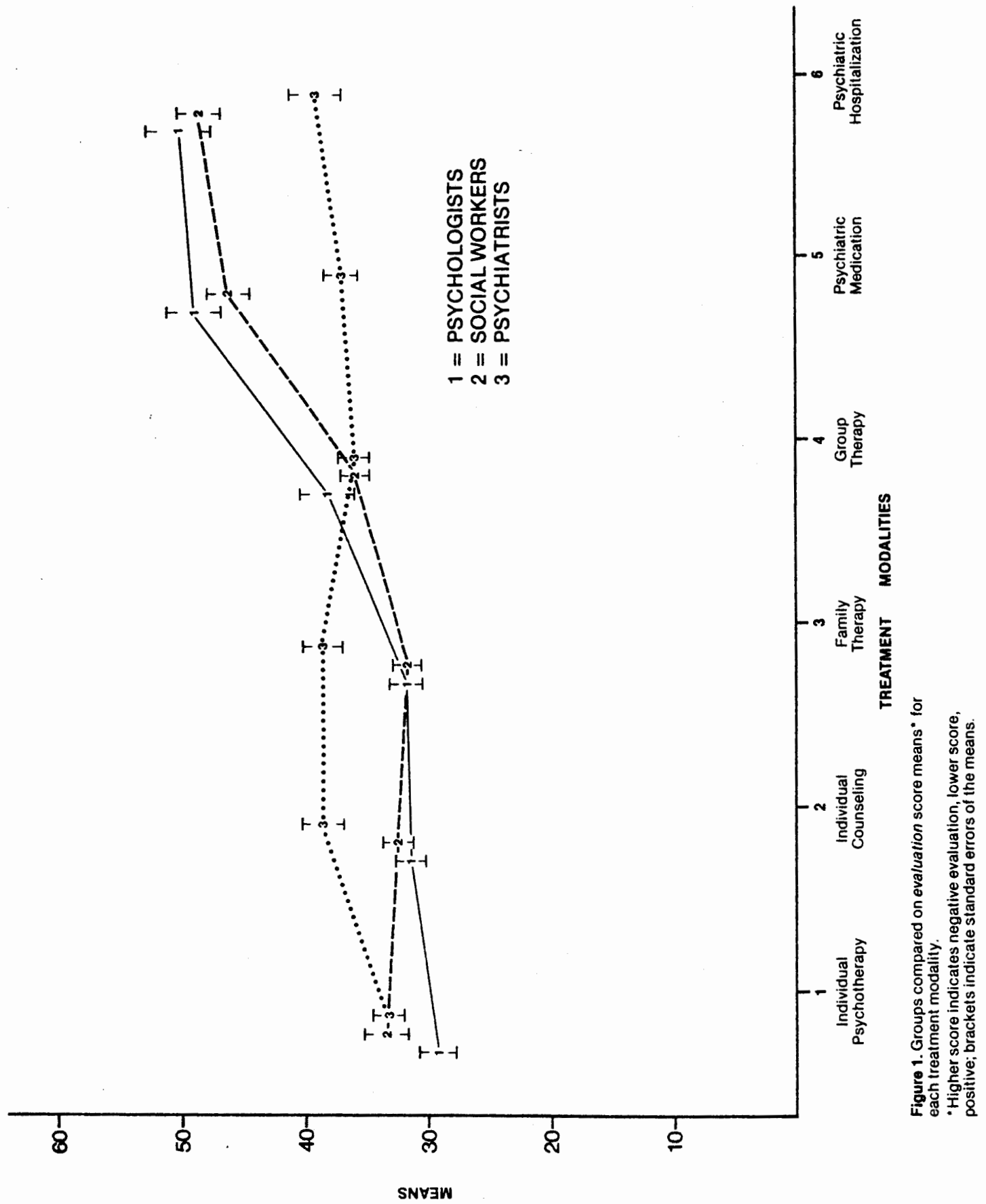


TABLE I

ATTITUDE SCORE (EVALUATION DIMENSION) MEANS AND STANDARD DEVIATIONS FOR EACH PROFESSIONAL GROUP

FOR EACH TREATMENT MODALITY

Group

Psychologists Social Workers Psychiatrists

$$
(n=32) \quad(n=34) \quad(n=32)
$$

$\begin{array}{cccc} & \text { Mean } & \text { Mean } & \text { Mean } \\ \text { Modality } & \text { (SD) } & \text { (SD) } & \text { (SD) }\end{array}$

\begin{tabular}{|c|c|c|c|}
\hline $\begin{array}{l}\text { Individual } \\
\text { Psychotherapy }\end{array}$ & $\begin{array}{l}29.44 \\
(8.29)\end{array}$ & $\begin{array}{l}33.47 \\
(8.93)\end{array}$ & $\begin{array}{l}33.28 \\
(7.92)\end{array}$ \\
\hline $\begin{array}{l}\text { Individual } \\
\text { Counseling }\end{array}$ & $\begin{array}{l}31.47 \\
(7.84)\end{array}$ & $\begin{array}{l}32.53 \\
(7.89)\end{array}$ & $\begin{array}{l}38.66 \\
(9.11)\end{array}$ \\
\hline $\begin{array}{l}\text { Fami } 1 \text { y } \\
\text { Therapy }\end{array}$ & $\begin{array}{l}31.94 \\
(7.95)\end{array}$ & $\begin{array}{l}31.71 \\
(6.58)\end{array}$ & $\begin{array}{l}38.69 \\
(9.00)\end{array}$ \\
\hline $\begin{array}{l}\text { Group } \\
\text { Therapy }\end{array}$ & $\begin{array}{l}38.38 \\
(12.13)\end{array}$ & $\begin{array}{l}35.21 \\
(7.58)\end{array}$ & $\begin{array}{l}35.59 \\
(7.73)\end{array}$ \\
\hline $\begin{array}{l}\text { Psychiatric } \\
\text { Medication }\end{array}$ & $\begin{array}{c}49.03 \\
(13.42)\end{array}$ & $\begin{array}{l}46.38 \\
(9.05)\end{array}$ & $\begin{array}{l}37.34 \\
(7.92)\end{array}$ \\
\hline $\begin{array}{l}\text { Psychiatric } \\
\text { Hospitalization }\end{array}$ & $\begin{array}{l}50.47 \\
(15.01)\end{array}$ & $\begin{array}{c}48.79 \\
(10.62)\end{array}$ & $\begin{array}{c}39.31 \\
(11.25)\end{array}$ \\
\hline
\end{tabular}

ogists is $9.32(\mathrm{df}=6,90 ; \mathrm{Q}<0.0001)$; for psychiatrists compared to social workers this statistic is 6.92 ( $\mathrm{df}=6$, $90 ; D<0.0001)$; whereas, for psychologists compared to social workers, this $E$ is $1.77(d f=6,90 ; p>0.10)$. 
The difference in attitude scores between the psychiatrists and the other two groups may be understood more clearly by considering the coefficients assigned to the treatment modalities by the one standardized linear discriminant function which separates the groups at a statistically significant level (Table II), and by examining the histogram plot of all (group-designated) cases on this function (Figure 2).

TABLE I I

COEFFICIENTS OF EACH MODALITY ON THE SIGNIFICANT STANDARDIZED LINEAR DISCRIMINANT FUNCTION

Treatment

Modality
Standardized Linear Discriminant Function Coef $\mathrm{icient}$
Individual Psychotherapy

Individual Counseling

Family Therapy

Group Therapy

Psychiatric Medication

Psychiatric Hospitalization
$-0.00464$

$$
-0.46112
$$

$$
-0.57352
$$

0.33013

$$
0.57431
$$




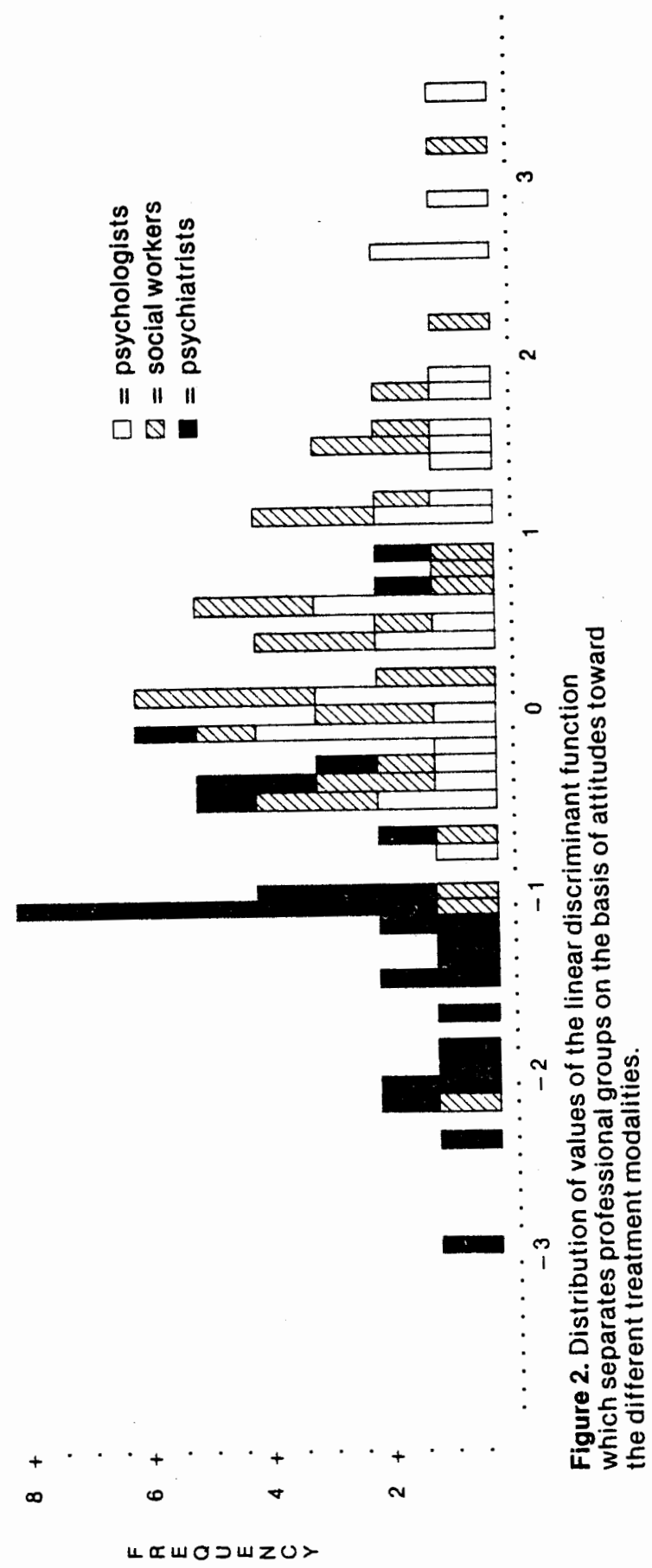


The linear discriminant function coefficients can be thought of as the best overall weights to assign the different modalities so that when attitude scores for the modalities are combined, the resulting discriminant function scores best separate the three groups. The one linear discriminant function used accounts for $87.3 \%$ of the variance for which the two such functions here algebraically possible could account.

On the basis of this function, $54.08 \%$ of the cases can be correctly classified into their professional group. As Table III shows, approximately one time in five a psychiatrist would be incorrectly classified as a social worker or psychologist, if only this linear discriminant function of their attitude scores were used as classifying information. As one might expect from previous observations, psychologists would be about as likely to be classified as social workers (and vice versa) if only their attitude scores and this discriminant function were used to predict professional group membership. Similarly, using such information, almost one-fourth of the social workers would be misclassified as psychiatrists. Thus, the usefulness of this function is to facilitate examination of groups' scoring differences, rather than to predict group membership consistently from treatment modality attitude scores. 
TABLE I I I

RESULTS OF CLASSIFICATION OF PROFESSIONALS INTO GROUPS ON THE BASIS OF THE LINEAR DISCRIMINANT FUNCTION

OF THEIR ATTITUDE SCORES

\begin{tabular}{lccccc}
$\begin{array}{l}\text { Actual } \\
\text { Group }\end{array}$ & $\begin{array}{c}\text { No. of } \\
\text { Cases }\end{array}$ & $\begin{array}{c}\text { Psycholo- } \\
\text { gists }\end{array}$ & $\begin{array}{l}\text { Social } \\
\text { Workers }\end{array}$ & $\begin{array}{c}\text { Psychia- } \\
\text { trists }\end{array}$ \\
\hline Psychologists & 32 & $15(46.9 \%)$ & $14(43.8 \%)$ & $3(9.4 \%)$ \\
Social Workers & 34 & $14(41.2 \%)$ & $12(35.3 \%)$ & $8(23.5 \%)$ \\
Psychiatrists & 32 & $2(6.3 \%)$ & $4(12.5 \%)$ & $26(81.3 \%)$ \\
\hline
\end{tabular}

The meaning of the particular coefficients found in Table II can be established with reference to the groups' attitude scores in Figure 1. Intergroup differences on Individual Psychotherapy are relatively small; the discriminant function coefficient is alsominimally weighted on this variable. On the variables Individual Counseling and Family Therapy the coefficients are much larger and are negatively signed; the means of attitude scores on these variables are significantly lower (more favorable) for psychologist and social worker groups than for the psychiatrists. On the variables Psychiatric Medication and Psychiatric Hospitalization the coefficients are relatively large and positively signed; on these variables the attitude scores are relatively higher (more unfavorable) for psychologists and social workers than for psychiatrists. 
These discriminant function coefficients give some indication of the magnitude and direction (favorableunfavorable) of the subject's overall scoring preferences. They also reflect the two-group (psychiatrists vs. psychologists and social workers) split of modality preferences, as the signs of modality coefficients switch with the inversion of the contrasting mean attitude scores of these two groups. The size of the coefficient for Group Therapy appears to be a consequence of its correlations with the other modalities, for no significant intergroup differences were found on this variable.

The overall attitude score similarities between psychologists and social workers and the difference of these groups from the psychiatrist group can most clearly be seen by an examination of Figure 2, a histogram showing the distribution by professional groups of all cases on the standardized linear discriminant function. The 1 inear combination implicit in the coefficients given in Table 2 yields a relatively homogeneous grouping of psychiatrists at low values of the discriminant function, while the psychologists and social workers tend to be mixed at higher levels. The histogram plot clearly shows how marked is this professional group separation.

It is clear that the professional groups differ in their attitudes toward the treatment modalities and that the differences consist primarily of the contrasting attitudes 
of the psychiatrists versus the other two groups. These findings can be productively explored in more detail. The reversal of the groups relative mean attitude score positions when Individual Counseling and Family Therapy are compared to Psychiatric Medication and Psychiatric Hospitalization (Figure 1) indicates a more complex picture. The group differences in attitude scores consist of an interaction of professional groups with specific treatment modalities. Table III summarizes the relevant $t$-tests for intergroup comparisons on each modality.

There were no significant intergroup differences in at itudes toward Individual Psychotherapy and Group Therapy. However, psychologists and social workers had more positive at titudes ( 1 ower attitude scores) toward Individual Counse ing and Family Therapy than did psychiatrists. In contrast to this, both psychologists and social workers had more negative attitudes (higher attitude scores) toward Psychiatric Medication and Psychiatric Hospitalization than did psychiatrists. Intergroup differences in attitudes toward treatment modalities vary in magnitude and direction depending on the treatment modality considered.

Examination of Figure 1 suggests an additional intergroup difference in score patterns on the treatment modalities. The attitude scores of psychiatrists appear to be in a narrower range than those given by psychologists and social workers. That is, the groups appear to differ in the 
extremeness of their responses: Systematic intergroup differences in response range appear to exist. To test this, for each case in all groups a "range score" was computed,

TABLE IV

BETWEEN-GROUP t-TESTS FOR COMPARISONS ON ATTITUDE

(EVALUATION DIMENSION) SCORE MEANS FOR

EACH TREATMENT MODAL ITY+

Groups

Compared

Modality
Psychologists Psychologists vs. Soc ia 1 Workers $(d f=64)$ vs. Psychiatrists $(\mathrm{df}=62)$
Social Workers

vs. Psychiatrists

$(d f=64)$

Individua 1

Psychotherapy

$-1.90$

$-1.90$

0.09

Individual

Counseling

$-0.55$

$-3.38 * *$

$-2.91 * *$

Family Therapy

0.13

$-3.18 * *$

$-3.58 * *$

Group Therapy

1.26

1.09

$-0.21$

Psychiatric

Medication

0.93

$4.24 * * *$

$4.32 * * *$

Psychiatric

Hospitalization

0.52

$3.37 * *$

$3.52 * *$

+ All entries refer to two-tail probabilities

$*_{R}<0.01$

$* * * R<0.001$

which is the absolute value of the difference of the highest and the lowest score on any of the six treatment modalities. 
For psychiatrists, the mean range score was 15.50 , with a standard deviation of 9.18 ; for social workers, the mean range score was 23.18 , with a standard deviation of 11.83; for psychologists, the mean range score was 27.78 , with a standard deviation of 15.06. A one-way analysis of variance done on these range scores indicated significant betweengroup differences $(E(2,95)=8.21, R<0.001)$. Betweengroup t-test comparisons of range score means indicated no significant differences for psychologists compared to social workers $(t=1.39, t$ wo-tail $D>0.10)$. However, the psychologists' range score mean was found to be significantly greater than that of the psychiatrists' $(t=4.06$, two-tail $R<0.001)$, as was the social workers' $(t=2.93$, two-tail $2<0.01$ ).

A more detailed analysis of the professional groups' attitudes can be achieved by an examination of within-group treatment modality preference patterns. Figure 1 suggests that within-group treatment modality preferences will be similar for social workers and psychologists, but not exactly the same. (Their profile shapes are similar, but not exactly congruent.) Furthermore, while psychiatrists often differ markedly from the other groups, in some instances their preference patterns do not appear to be unique. Tables IV, V, and VI present $t$-test results of within-group treatment modality comparisons for all groups. 


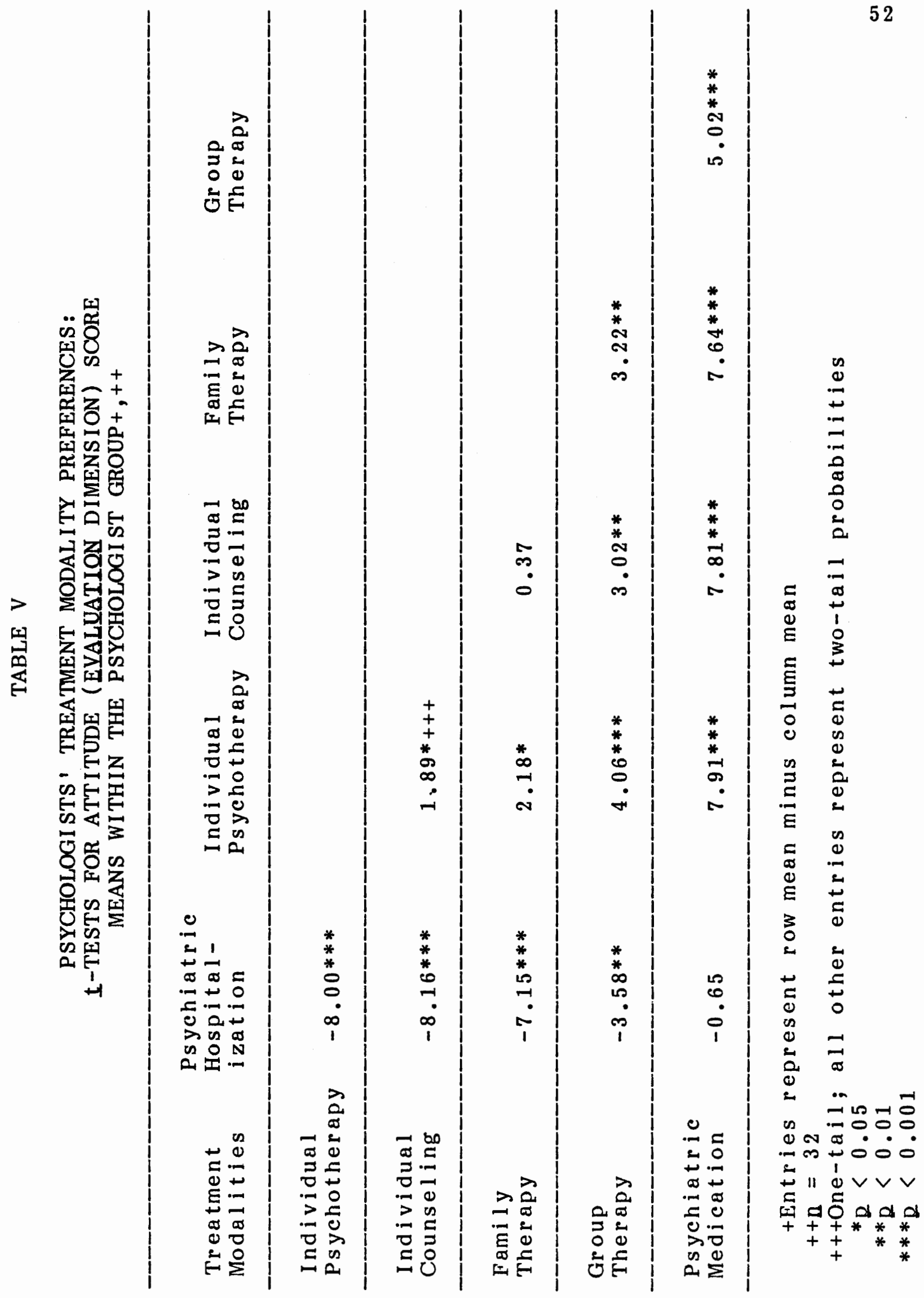




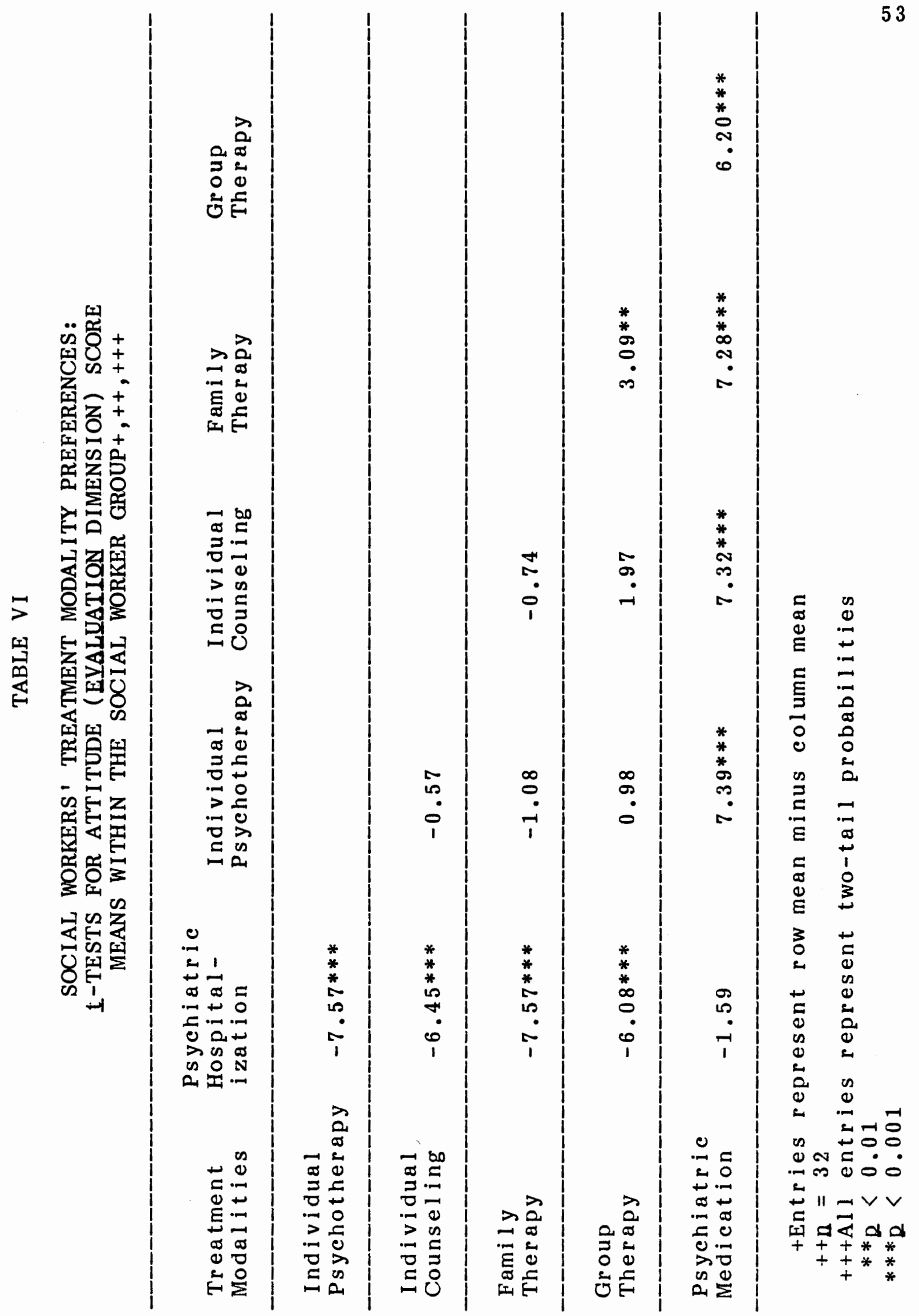




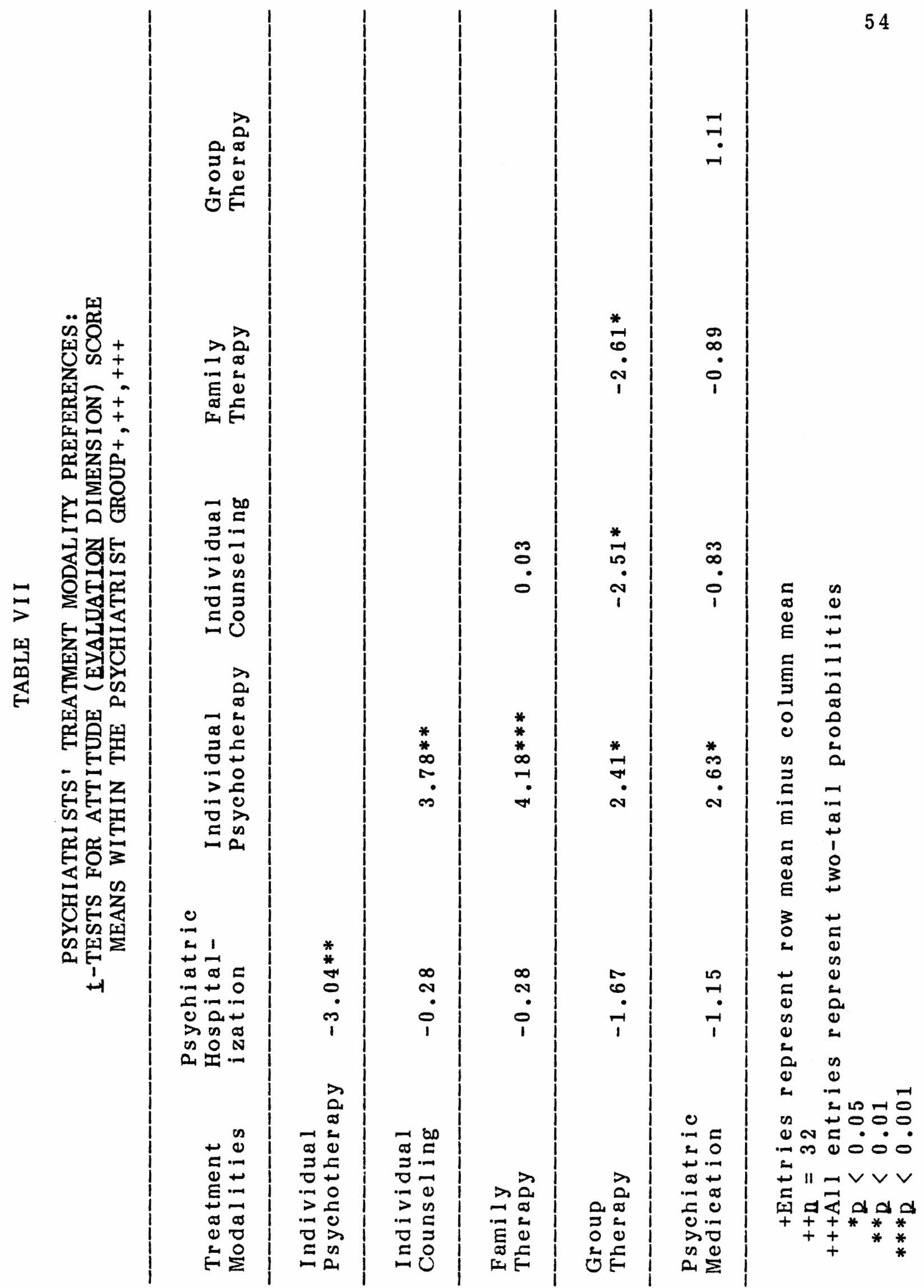


It is striking that psychologists and psychiatrists are alike in prefering Individual Psychotherapy over every other treatment modality, while social workers prefer it only over Psychiatric Medication and Psychiatric Hospitalization (just as they prefer every other modality over these twol and indicate no evaluative difference between Individual Psychotherapy and the remaining modalities. All groups are similar in that none indicates an evaluative preference separating Psychiatric Medication from Psychiatric Hospitalization and all evaluate Family Therapy similarly to Individual Counseling. However, Individual Counseling presents the most diverse picture of within-group preference patterns. Psychologists and social workers evaluate it more positively than Psychiatric Medication and Psychiatric Hospitalization, while psychiatrists evaluate it similarly to these variables. Furthermore, psychologists evaluate Individual Counseling more positively than Group Therapy, social workers indicate no difference between the two, and psychiatrists evaluate Group Therapy more positively than Individual Counseling .

The remaining preference patterns again indicate the relative separation of the psychiatrists: They evaluate Group Therapy more positively than Family Therapy, while both psychologists and social workers evaluate Family Therapy more positively than Group Therapy; psychologists and social workers evaluate both Family Therapy and Group 
Therapy more positively than both Psychiatric Medication and Psychiatric Hospitalization, while psychiatrists indicate no evaluative differences between Psychiatric Medication or Psychiatric Hospitalization and Group Therapy nor between Psychiatric Medication or Psychiatric Hospitalization and Family Therapy. Generally, the within-group preference patterns sustain the finding of psychologist-social worker evaluative commonalities, with notable exceptions involving the variables Individual Psychotherapy and Individual Counseling •

A further exploration of the professional groups characterization of Individual Psychotherapy and Individual Counseling was done by comparing these two variables along the petency and activity dimensions. A multivariate analysis of variance (Tatsuoka, 1971) was used to determine if responses to the Individual Counseling and Individual Psychotherapy modalities on the activity and petency dimensions differed significantly from group to group. This analysis confirmed that the groups differ at a statistically significant level (Wi $1 \mathrm{ks}$ 'Lambda $=0.799, E_{(4,188)}=5.57$, D ( 0.001). However, Retency dimension ratings of Individual Counseling and Individual Psychotherapy did not provide information which significantly differentiated the groups. For the Individual Counseling and Individual Psychotherapy activity dimension ratings it was found that every professional group differed from each other group: The E 
statistic corresponding to Hotellings' $T^{2}$ for psychiatrists compared to psychologists is 7.32 ( $d f=2,94 ; R<0.01)$; for psychiatrists compared to social workers this $E$ statistic is $6.60(\mathrm{df}=2,94 ; \mathrm{R}<0.01)$; and for psychologists compared to social workers this $E$ is 3.04 (df $=2,94 ; \mathrm{D}<$ $0.05)$. Summary statistics and t-tests relevant to these considerations appear in Tables VIII, IX, X and XI.

\section{TABLE VIII}

INDIVIDUAL COUNSELING AND INDIVIDUAL PSYCHOTHERAPY ROTENCY DIMENSION SCORE MEANS AND STANDARD DEVIATIONS FOR EACH PROFESSIONAL GROUP

\begin{tabular}{|c|c|c|c|}
\hline Group & $\begin{array}{c}\text { Psychologists } \\
(n=32)\end{array}$ & $\begin{array}{c}\text { Social Workers } \\
(n=34)\end{array}$ & $\begin{array}{c}\text { Psychiatrists } \\
(n=32)\end{array}$ \\
\hline Modality & $\begin{array}{c}\text { Mean } \\
(\mathrm{SD})\end{array}$ & $\begin{array}{c}\text { Mean } \\
(\mathrm{SD})\end{array}$ & $\begin{array}{c}\text { Mean } \\
(\mathrm{SD})\end{array}$ \\
\hline $\begin{array}{l}\text { Individual } \\
\text { Counseling }\end{array}$ & $\begin{array}{l}16.13 \\
(2.69)\end{array}$ & $\begin{array}{l}16.21 \\
(2.09)\end{array}$ & $\begin{array}{l}17.22 \\
(2.74)\end{array}$ \\
\hline $\begin{array}{l}\text { Individual } \\
\text { Psychotherapy }\end{array}$ & $\begin{array}{l}14.69 \\
(2.46)\end{array}$ & $\begin{array}{l}15.41 \\
(2.61)\end{array}$ & $\begin{array}{l}14.91 \\
(2.93)\end{array}$ \\
\hline
\end{tabular}


TABLE IX

INDIVIDUAL COUNSELING AND INDIVIDUAL PSYCHOTHERAPY

ACTIYITY DIMENSION SCORE MEANS AND

STANDARD DEVIATIONS FOR EACH

PROFESSIONAL GROUP

\begin{tabular}{lccc}
$\begin{array}{l}\text { Group } \\
\text { Modality }\end{array}$ & $\begin{array}{c}\text { Psychologists } \\
(n=32)\end{array}$ & $\begin{array}{c}\text { Social Workers } \\
(n=34)\end{array}$ & $\begin{array}{c}\text { Psychiatrists } \\
(\mathrm{n}=32)\end{array}$ \\
\hline $\begin{array}{l}\text { Mean } \\
\text { Individual }\end{array}$ & $\begin{array}{c}\text { Mean } \\
(\mathrm{SD})\end{array}$ & $\begin{array}{c}\text { Mean } \\
(\mathrm{SD})\end{array}$ \\
\hline Counseling & $\begin{array}{l}14.28 \\
(3.38)\end{array}$ & $\begin{array}{c}12.88 \\
(3.39)\end{array}$ & $\begin{array}{c}15.25 \\
(2.58)\end{array}$ \\
\hline Individual & 11.72 & 12.77 & 14.25 \\
Psychotherapy & $(2.74)$ & $(2.88)$ & $(2.52)$ \\
\hline
\end{tabular}

TABLE X

INDIVIDUAL COUNSELING COMPARED TO INDIVIDUAL PSYCHOTHERAPY: 1-TESTS FOR WITHIN-GROUP COMPARISONS ON THE ACTIYITY DIMENSION+

Group

Psychologists Social Workers Psychiatrists $(n=32) \quad(n=34) \quad(n=32)$

\pm value

$3.53 * *$

0.16

1.59

tAll entries refer to two-tail probabilities

$*^{*} \mathrm{Q}<0.01$ 


\section{TABLE XI}

1-TESTS FOR BETWEEN-GROUP DIFFERENCES ON THE ACTIVITY

DIMENSION FOR INDIVIDUAL COUNSELING AND

INDIVIDUAL PSYCHOTHERAPY MODALITIES+

\begin{tabular}{|c|c|c|c|}
\hline Groups & $\begin{array}{c}\text { Psychologists } \\
\text { vs. Social } \\
\text { Workers } \\
(\mathrm{df}=64)\end{array}$ & $\begin{array}{c}\text { Psychologists } \\
\text { vs } \\
\text { Psychiatrists } \\
(d f=62)\end{array}$ & $\begin{array}{c}\text { Social Worker } \\
\text { vs. } \\
\text { Psychiatrists } \\
(\mathrm{df}=64)\end{array}$ \\
\hline $\begin{array}{l}\text { Individual } \\
\text { Counseling }\end{array}$ & 1.68 & -1.29 & $-3.20 * *$ \\
\hline $\begin{array}{l}\text { Individual } \\
\text { Psychotherapy }\end{array}$ & -1.51 & $-3.85 * * *$ & $-2.23 *$ \\
\hline
\end{tabular}

+All entries represent two-tail probabilities

${ }^{*} \mathrm{Q}<0.05$

$* * 0<0.01$

$* * * p<0.001$

As a group, psychologists see Individual Counseling as less active than Individual Psychotherapy $(t=3.53$, twotail $2<0.01)$. For the psychiatrist group no significant difference was found between these two variables on the actiyity dimension $(t=1.59$, two-tail $\mathrm{p}>0.10)$. Similarly, for the social worker group there was no significant difference between Individual Counseling and Individual Psychotherapy on the actiyity dimension $(t=0.16$, two-tail D $>0.10$ ).

Between-group $t$-test comparisons of these variables indicate that psychologists see Individual Psychotherapy as significantly more actiye than do psychiatrists $(t=-3.85$, 
two-tail $\mathrm{R}<0.001$ ) and that social workers see both Individual Counseling and Individual Psychotherapy as significantly more getive than do psychiatrists $(t=-3.20$, twotail $R<0.01 ; t=-2.23$, two-tail $R<0.05$, respectively). Psychologists do not see Individual Counseling significantly differently than psychiatrists on the actiyity dimension, and psychologists do not differ from social workers. for either variable on the activity dimension.

An additional dimensional analysis was done to explore possible differences between Individual Counseling and Individual Psychotherapy. For each group on both the eyalua= tien and ectivity dimensions, Individual CounselingIndividual Psychotherapy "difference scores" were computed. Table XII provides means and standard deviations of these scores for each professional group.

\section{TABLE XII}

INDIVIDUAL COUNSELING-INDIVIDUAL PSYCHOTHERAPY DIFFERENCE SCORE MEANS AND STANDARD DEVIATIONS ON EVALUATION AND ACTIYITY DIMENSIONS FOR EACH PROFESSIONAL GROUP

Group

Dimension
Psychologists Social Workers

$$
(n=32)
$$

Mean

( SD)

$$
(n=34)
$$

Mean

( SD)
Psychiatrists

$(n=32)$

Mean

(SD)
Exaluation

Activity

2.03
$(6.09)$

2.03
$(6.09)$
$-0.94$

(9.71)
5.38

$(8.04)$ 
Group means of these difference scores were compared, using t-tests between groups for all combinations of groups, with difference score means on each dimension considered separately. These comparisons indicate whether any professional group sees the separation of these two modalities significantly differently than the other groups on either the exaluation or the actiyity dimension. These comparisons are presented in Table XIII.

\section{TABLE XI I I}

INDIVIDUAL COUNSELING-INDIVIDUAL PSYCHOTHERAPY DIFFERENCE SCORES: 1 -TESTS FOR INTERGROUP COMPARISONS ON THE EYALUATION AND ACTIYITY DIMENSIONS+

\begin{tabular}{|c|c|c|c|}
\hline Group & $\begin{array}{c}\text { Psychologists } \\
\text { vs. Social } \\
\text { Workers } \\
(d f=64)\end{array}$ & $\begin{array}{r}\text { Psychologists } \\
\text { vs. } \\
\text { Psychiatrists } \\
(d f=62)\end{array}$ & $\begin{array}{c}\text { Social Workers } \\
\text { vs . } \\
\text { Psychiatrists } \\
(\mathrm{df}=64)\end{array}$ \\
\hline Evaluatien & 1.50 & -1.87 & $-2.87 * *$ \\
\hline Activity & $2.36^{*}$ & 1.62 & 0.906 \\
\hline
\end{tabular}

+All entries refer to two-tail probabilities

$*_{R}<0.05$

$* * R<0.01$

On neither of the dimensions were the Individual Counseling-Individual Psychotherapy difference score means significantly different for the psychologists compared to the psychiatrists. The difference score means on the activ= 
62

iffy dimension were significantly greater for psychologists compared to social workers. However, the difference score means are not significantly different on the evaluation dimension for these two groups. Social workers had signifycanty smaller difference score means compared to psychiatriste for the evaluation dimension. However, on the actin= ity dimension, no significant difference between difference score means was found for these two groups. 
CHAPTER IV

\section{DISCUSSION}

\section{INTERGROUP DIFFERENCES AND HYPOTHESES}

Perhaps the most salient finding of this study is the extreme separation of the psychiatrist group from a relatively homogeneous grouping of clinical psychologists and social workers on the basis of attitudes towardmental health treatment methods. Although some important differentiations of psychiatrists from the other two groups were noted previously, the treatment methods rated were diverse and one might expect more diversity in evaluations over all groups, such as the intermediate placement of psychologists between more extremely separated psychiatrists and social workers hypothesized for reasons stated earlier.

On the other hand, there are reasons to expect that an alternative to the hypothesized differences might simply be an intergroup homogeneity greater than that found here. Goldman and Mendelsohn (1969) found a high degree of agreement among psychiatrists, clinical psychologists, and psychiatric social workers about what constitutes a successful outcome of mental health treatment. Consistent with this, Henry, Sims, and Spray (1971) propose that over time the performance of professionals from all three groups will 
become similar, noting that "in their post-training lives and their professional maturity, they performessentially the same resultant activity -- psychotherapy" (p. 181). If the desired outcome is the same across groups, and if the central activity of professional maturity is designated consistently across all groups as "psychotherapy," then the most logical alternative to interprofessional differentiation regarding treatment method preferences would be simply a lack of any such intergroup differences.

The finding here was neither the originally hypothesized diversity nor such alternatively plausible homogeneity, but a distinct separation of psychiatrists from the relatively indistinguishable meshing of psychologists and social workers. There appear to be at least two possible explanations for these difference findings: acceptance or rejection of the medical-model theory in clinical mental health practice, and sociopolitical concerns of professionally autonomous accessibility and/or legitimacy of specific treatment methods for specific professional groups. The data of this study are not sufficient to resolve which explanation best accounts for the present findings. It seems plausible and likely that both abstract (theoretical/ training) and pragmatic (professional self-interest) explanations are relevant. Both factors may contribute together to causing the differences observed here. Both will be considered in the following pages, beginning with a description 
of the meaning of the term "medical model" and its relevance here, and continuing with a discussion which includes indications of the possible place of both the medical model and professionally autonomous/legitimate access factors in the findings of this study.

A distinct separation of psychiatrists from an intermixed cluster of psychologists and social workers similar to that found here was found when Cohen and Struening (1963) differentiated groups on the basis of scales measuring opinions about mental illness. They found psychiatrists higher than psychologists and social workers on dimensions of Authoritarianism and Social Restrictiveness (restricting the mentally ill from society) and lower than psychologists and social workers on dimensions measuring support for community mental health treatment and acceptance of interpersonal (nonorganic) causes for mental illness.

Henry, Sims, and Spray (1971) emphasize a critical training difference which divides these professional groups in a way which appears particularly relevant to the Cohen and struening (1963) study and to the present findings: "[E] ach profession and its related training setting have maintained significant degrees of distance from other professions. The central dividing line has been the commitment to the medical image, as represented in the training for the M.D... The psychologist and the social worker have neither the M.D. nor its generally concomitant assumptions in med- 
ical ideology" (p. 4). The main assumptions in medical ideology which are likely to separate psychiatrists from nonmedical providers of mental health care are those of the "medical model," as is clear from Blaney's (1975) analysis of the professional and sociopolitical implications of the usage of the medical model in the mental health care professions.

Siegler and Osmond (1974) have analyzed many models of mental health treatment in great detail and write with authority and depth on the multiple characteristics of the medical model. An important conclusion of their work is that the medical model basically consists of 1) an especial 1 y powerful kind of "medical authority," and 2) a "sick role." The medical authority component of the medical model gives only a physician the societally sanctioned power to place a person in the sick role.

There are three elements of the sick role emphasized by Siegler and Osmond (1974) which are important for consideration here. First, the role is conferred on an indixidual who cannot help being ill and cannot get well by an act of decision or will; the presence of an organic problem (usually underlying a possible variety of surface symptoms) is implied - this idea has been extended through psychoanalytic thought to include nonorganic intrapsychic problems which are beyond the afflicted person's immediate conscious control. Second, the sick individual is expected to want to 
get well as soon as possible, to seek appropriate help (primarily that of a physician) and to cooperate with that help with the goal of getting well. Finally, the sick individual has a right to a blame-free sick role exempt from normal responsibilities. Most notably with respect to mental i 11 ness, if the sick person does not demonstrate the justmentioned desire for wellness, help-seeking, and cooperation with treatment, then society, the family, and the physician have a duty (and an implied authority) to provide care.

There is one other important characteristic of the medical model noted by Blaney (1975) as an important factor tending to separate medical providers of mental health care from other providers of such care. This is the importance of diagnosis. Diagnosis is the noting of behaviors and/or physical signs by which identifiedmental health problems are labelled as belonging to previously defined pathological categories, directly analogous to the formal illness/disease syndrome groupings of the nosology used in general medicine. The importance of diagnosis in psychiatry has been well documented (Connaughton, 1977; Bowden, Humphrey, and Thompson, 1980; Guze, 1977, 1978), as has opposition to such activities in mental health care provision (Sarbin, 1967; Szasz, 1957; Tarrier, 1979).

Thus with respect to mental disorders, the medical model implies that the psychiatrist has unique, quite powerful authority over the individual patient, who petitions the 
physician for diagnosis and care in response to helpless victimization by internal pathological processes.

Of final note, Siegler and Osmond (1974) maintain that because of the powerful social necessity of structuring dealing with illness and death, the medical model and the physician's role as the implementer of the model are deeply embedded cultural phenomena. They therefore claim that any person who goes through the intense medical socialization process (i.e., receives an M.D. degree) will always maintain at some level a basic medical identification and perspective. In particular, they emphasize, this is and should be true of psychiatrists.

These considerations concerning the medical model are helpful in understanding the findings of this study. They il luminate the treatment approaches which may be considered legitimate elements of the professional roles of psychiatrists as opposed to psychologists and social workers. The findings of professional intergroup differences may be most parsimoniously explained in terms of those activities which are considered by each professional group as being within or excluded from their professional role functions. Not only is the medical model relevant here, so is an awareness of the diverse treatment methods accepted as within the purview of social work (Arkava, 1973; Turner, J.B., 1977; Whittaker, 1974 ) and the diverse foci of the professional efforts of clinical psychologists (Sundberg, Tyler, and Taplin, 1973; 
We iner, 1976$)$.

Differences in areas of professionally accepted legitimate treatment provision are indicated by the findings that the psychologist and social worker groups did not differ from each other in the evaluation of any modality, while both these groups had more negative attitudes toward Psychiatric Medication and Psychiatric Hospitalization and more positive attitudes toward Individual Counseling and Family Therapy than did the psychiatrist group. Apparently, treatment values (and professionally sanctioned methods of care provision) are shared extensively by psychologists and social workers, but are divergent from the treatment values and methods of psychiatrists.

There is a treatment valuation/provision overlap of all three groups, demonstrated by their similar ratings of Individual Psychotherapy and Group Therapy. As described previously, Individual Psychotherapy is a treatment modality recognized as being legitimately provided by all three professional groups. In part, this may be due to the lack of a universally accepted, fundamental definition of psychotherapy (Heiman, 1978; Orne, 1975; Schwab, 1978). This ambiguity might facilitate the interpretation by each professional group of Individual Psychotherapy as a method within their purview.

Group Therapy is also regarded as legitimately within the professional arena of all three groups. This treatment 
method falls within the province of the medical model, since the treatment process can be conceptualized as focusing on the sick indixidual in a group setting (Day and Semrad, 1978; Kissen, 1976; Meiers, 1946; Sadock, 1975) and, despite the presence of a group of persons, still can be done from an individual psychoanalytic or physician-authority based theoretical perspective (Meissner and Nicholi, 1978; Kovel, 1976; Pinney, Jr., 1970), which is consistent with the previously described medical model. The legitimate place of group treatment methods in social work is documented extensively (Douglas, 1979 ; Northen, 1969; Turner, 1978). That this method is recognized as a legitimate approach for clinical psychologists, too, is clearly substantiated (Lubin, 1976 ; Mul lan and Rosenbaum, 1962; Sundberg, Tyler, and Taplin, 1973; Wellner, 1977).

The separation of the psychiatrists from the other groups on the Psychiatric Medication and Psychiatric Hospitalization modalities seems most likely to be a function of the access psychiatrists have to these methods and the methods' inherent place in the medical model of treatment, as well as the inaccessibility of these options to professionally autonomous social workers and psychologists. Of 1 ikely relevance is the current apparent necessity of the use of a (medical) diagnosis in the provision of such treatment. As previously noted, "diagnosis" is an important part of the medical model and is an activity of relatively great 
import to psychiatrists as compared to social workers and psychologists. Thus, treatment necessarily involving formal diagnosis (as derived from medical-model diagnostic procedures) might be expected to separate the groups.

The long-standing conflict between the profession of psychiatry and the professions of social work and psychology regarding which profession(s) may legitimately provide care for the emotionally/psychologically distressed (Goode, 1969; Rogers, 1980) may be relevant in the psychologists' and social workers' rejection of medically oriented treatment here. Also, these findings may be related to the historical development of much of psychiatry within a psychiatric hes= Rital context (Connaughton, 1977), while clinical psychology developed from a scientific academic context (Hathaway, 1958; Orne, 1975; Shakow, 1975) and social work through a community service context (Hersey, Jr., 1977; Modlin, 1975). Finally, the clear tendencies of clinical psychologists and social workers towards an antimedical-model and antidiagnosis position has been documented (Morrison and Hanson, 1978; Morrison and Nevid, 1976), as has the possible philosophical opposition of clinical psychologists to the use of medication in treating mental health problems (Bascue and Zlotowski, 1980).

The separation of psychiatrists from the other two groups on the Individual Counseling and Family Therapy variables constitutes a similar pattern. Individual Counseling 
can be readily seen as a reference to a social work process; the counseling/counselor designation is acknowledged frequently in the professional literature of social work (Hersey, Jr., 1977; Turner, 1977). Furthermore, with counseling psychology being recognized as a distinct area of psychological study represented as a division of the American Psychological Association, the acceptance by clinical psychologists of Individual Counseling as referring to a process accessible for psychologists' legitimate use seems straight forward.

In contrast, psychiatry displays no development of or explicit, extensive acknowledgement of "counseling" methods per se for its use. Moreover, it has been noted that "Psychiatry...enjoys the most strongly defined role in the mental health field" (Heiman, 1978, p. 30), and that psychiatry has been greatly concerned with the development of permanently curative mental health treatment (Orne, 1975). Since the term "counseling" carries with it possible associations of a confused, perhaps palliative treatment of lesser consequence (Stefflre, 1972) and also may imply a relatively open interpersonal exchange between the counselor and counselee (Carkhuff and Berenson, 1977; May, 1967; Rogers, 1980) rather than the medical authority/sick person roles consistent with the medical model, the negative rating of Individual Counseling by psychiatrists relative to the other two groups is understandable. 
Family Therapy is also relatively negatively evaluated by psychiatrists. It has been noted that psychiatry has failed to adopt the Family Therapy treatment method (Ackerman, 1967; Connaughton, 1977). This may be due in great part to the fact that in this therapy method the entire family is generally seen together, complete as a natural system, with the whole family itself as the unit to be treated. Thus, there is no individual who is the focus of a diagnosis; rather, familial problems (including apparent individual psychopathology) are understood as dysfunctions within the family social system which necessarily involve more than one individual (Bell, 1975). Therefore, there is no place in this treatment method for psychiatric diagnoses derived from traditional medical-model concepts.

Also, Connaughton (1977) notes Zilback's (1974) assertion that the family treatment approach does not fit into the traditional medical treatment categories of child psychiatry or adult psychiatry, and thus the assimilation of this modality by traditional psychiatry is problematical. That is, the Family Therapy modality does readily fit the traditional medical-model concepts of individual treatment, diagnosis, and ultimate physician autonomy which have been historically fundamental in psychiatry.

In contrast, Family Therapy is easily understood as a social work process, given the extensive involvement of social work with families throughout the development of the 
profession and the widely noted special professional skills of social workers with children, parents and families (Beck, 1964; Modlin, 1975). This emphasis is supported by present findings of social work's preference for Family Therapy over the Group Therapy modality, which may be associated with medical-model treatment efforts. That clinical psychologists have positively assimilated the Family Therapy treatment approach is evident from the professional literature (Fox, 1976; Winter, 1971). This acceptance of the Family Therapy method may be a function of the analytical, social science emphasis of clinical psychology, providing a willingness to conceptualize, develop and evaluate treatment at different levels of analysis (e.g., individuals, small groups and families, or larger social systems, including communities and society) (Krech, Crutchfield, and Ballachey, 1962 ; Sundberg, Tyler, and Taplin, 1973). Since it is the family as a system that is studied and treated with the Family Therapy method, the acceptance of "social systems" thinking which is present in clinical psychology would prove important in acceptance of this method by psychologists. In their willingness to consider treatment at the individual, family and societal levels, clinical psychologists are much like social workers.

Haley's (1975) extensive description of many dimensions of the family therapy treatment process is especially relevant to the findings here. Haley notes the irrelevance of 
psychiatric diagnostic process to family therapy treatment methods. He also specifies that training psychiatrists to do family therapy and social interventions is to train them to work as social workers and psychologists already do. Thus, the separate identity and higher status of psychiatrists in the clinical community would be jeopardized if family therapy methods were fully accepted by psychiatry. Haley describes the critical import of this therapeutic modality for interprofessional differentiation:

As this form of therapy intrudes more into the field, the issue of the difference between the professionals also arises. When the problem unit was the individual, the psychologist, social worker, and psychiatrist each had a separate function defined by their training. When the unit is the family, all clinicians tend to do the same work and the differences between the professionals become obscured. This situation has provided a problem for many psychiatry departments. If residents are trained with an individual orientation and in the use of medication, they can maintain their professional identity and $s$ tatus in the field as the most extensively trained professionals. Yet, if the orientation of therapy becomes more social so that the emphasis is on changing families and other natural groups, the psychiatrist trained to use medication and psychodynamic therapy will be regarded as old fashioned and not relevant to therapy. (Haley, 1975 , p. 1885 ).

Within this context, psychiatry's contrasting level of approval of Family Therapy relative to social work and clinical psychology is understandable.

As noted previously, the present data are not sufficient to designate which explanation -- theoretical subscription versus prescription of the medical model, or profes- 
sional autonomy and/or legitimacy of treatment method access -- best explains the major intergroup differences found here. However, the range scores (which indicate that psychologists and social workers are more extreme in their ratings than psychiatrists) and the more consistently positive attitude scores of psychiatrists may be seen as supportive of an autonomous, legitimate access explanation, as described subsequently.

The finding that at itude scores over all modalities are in a narrower range for psychiatrists than for psychologists and social workers, who did not differ from each other in this respect, is noteworthy. Several considerations seem relevant to possible explanation of these differences in overall extremeness of ratings.

First, it is conceivable that psychiatrists may perceive all the rated treatment modalities as of some possible use to them or as being accessible to them if necessary, inasmuch as it has been stated that "the medical psychotherapist...has all techniques available to him" (Mittel, 1978 , p. 35) and that psychiatry as a professional group sees itself as "able to utilize all available forms of therapy" (Lief, 1960, p. 69). Furthermore, psychiatry sees itself as having a "uniquely important role" (Eaton, Jr. and Goldstein, 1980 , p. 67) and as participating "in medicine...and in all those disciplines, theories, and ideologies which influence the shape and meaning of psychotherapy 
generally" (Cottle and Whitten, 1980 , p. 40$)$; moreover, it is noted that "psychiatry...is truly the parent of the art of psychotherapy (Cottle and Whitten, 1980, p. 40). Also, House, Miller, and Schlachter (1978) note that "modern psychiatry prepares the resident to treat the full spectrum of psychiatric disorders, employing both somaticpharmacologic as well as psychological methods" (p.470). This professional self-concept might moderate any tendency to be extremely negative about the treatments, although preferences relative to other groups and consistent with the dominant medical model could obviously be expressed.

Second, the clinical psychologists and social workers are clearly extremely negative about Psychiatric Hospitalization and Psychiatric Medication compared to their ratings of the other modalities and to the psychiatrists' ratings. Since the other methods can all be understood theoretically and practiced clinically from a nonmedical-model viewpoint, much of the extremeness-of-ratings findings of social workers and psychologists may be due to their apparent rejection of the medical model and medical treatments not autonomously accessible to them. It may also be due in part to an antimedical reactive enthusiasm for the more clearly nonmedical treatment procedures, Individual Counseling and Family Therapy, which they so clearly evaluate more positively than do the psychiatrists. Indeed, such a relative rejection of the medical model by social work and (especi- 
ally) clinical psychology professionals has been previously noted (Morrison and Hanson, 1978; Morrison and Nevid, 1976), as have the sociopolitical conflicts involving these groups regarding the legitimacy of the medical model and medical perogatives in mental health care (Blaney, 1975; Goode, 1960 ; Orne, 1975 ; Rogers, 1980). These considerations may at least partially explain the interprofessional differences found here in extremeness of ratings.

A perspective on the extremeness-of-ratings finding which is useful in better understanding the professionals' at itudes is that of at itude score means compared to an "absolute neutrality". That is, mean eyaluation scores for each group on all modalities (Table I) may be examined with reference only to an absglutely neutral position defined as the sum of the midpoints of the semantic differential scales constituting the eyaluation dimension measure. Recall that herefor each scale a 4 constitutes a neither positive nor negative semantic differential score, so a perfectly neutral attitude score for the twelve eyaluation scales would be 48 . It is informative to compare mean eyaluation scores for each group and modality directly to this absolutely defined neutrality, rather than to rely only upon relative, intergroup comparison scores to find meaning in these data.

In this sense - - with reference to an absolutely neutral position on the semantic differential scales -- it is noteworthy that the mean exaluation scores on all modalities 
for the psychiatrist group indicate consistent positive judgments. Thus, the psychiatrists' absolute scores (not scores relative to the other groups') support the abovedescribed ideas of their professional view that they may use (and therefore must at least somewhat positively accept) virtually all treatment methods.

Furthermore, for psychologists and social workers reference to overall exaluation score means in comparison to an absolutely neutral exaluation score indicates that these two groups are negative or neutral regarding psychiatric Medication and Psychiatric Hospitalization, while they are clearly favorable toward all other methods. In this nonrelative sense, with reference to absolute neutrality as defined by the midpoints of the exaluation scales, no group radically rejects any treatment method. In this sense most methods are regarded at least somewhat positively by all groups, with psychologists and social workers exhibiting clear reservations only about approval of Psychiatric Medication and Psychiatric Hospitalization.

Psychologists and social workers, in contrast to psychiatrists, can presently have no legitimate (legal) autonomous use of Psychiatric Medication or Psychiatric Hospitalization. It is noteworthy that their absolute attitude scores for these modalities alone are clearly negative or cautiously neutral. The quite positive absolute attitude score means on Individual Counseling and Family Therapy for 
both the psychologists and social workers seem to indicate a highly favorable attitude toward these modalities (which are clearly accessible and legitimized for these two groups), irrespective of the medical model. Within-group comparisons (Tables $V$ and $V I$ ) are consistent with these absolute scores: within either the psychologist or social worker group no significant evaluative differences are found for Individual Counseling compared to Family Therapy, but for both groups these two modalities are seen as significantly more positive than either Psychiatric Medication or Psychiatric Hospitalization.

Furthermore, al though Individual Psychotherapy max be regarded as a treatment based on medical-model constructs (e.g., diagnosis, internally generated pathology), both psychologists and social workers presently may legitimately perform this activity, and both prefer it over the clearly medically based treatments Psychiatric Medication and Psychiatric Hospitalization, which they cannot autonomously use.

Although psychiatrists may be seen traditionally as having limited use of Individual Counseling and Family Therapy, these methods are not legally proscribed to them, and psychiatrists are at least somewhat positive about these methods in an absolute sense. Also, within the psychiatrist group Family Therapy, Individual Counseling, Psychiatric Hospitalization and Psychiatric Medication are not evaluated 
as being significantly different, although all these methods are seen more negatively than Individual Psychotherapy (Table VII), which both fits the medical model and may provide high status/monetary rewards to its practitioners.

Such findings may indicate some ambiguity in the place of the medical model in determining mental health treatment method evaluations, even for medically trained practitioners. Overall, the above points may indicate the operation of an autonomous/legitimate professional access factor influencing treatment method evaluations, either independent of or in combination with medical-model considerations.

\section{INDIVIDUAL COUNSELING COMPARED TO INDIVIDUAL PSYCHOTHERAPY}

\section{Intragroup Differences}

The findings that both psychologists and psychiatrists (within each separate professional group) have a more positive attitude toward Individual Psychotherapy than toward Individual Counseling and the fact that psychologists also see Individual Psychotherapy as more actiye than Individual Counseling may be expressions of ideas and events noted in the literature.

For instance, Individual Psychotherapy has been described in a variety of professional sources in terms implying that it is in a broad sense a greater, more esteemed process than Individual Counseling (Stefflre, 1972). Thus, Individual Psychotherapy may be regarded, broadly speaking, 
as a more complex and difficult and process than Individual Counseling. This may account for the eygluation and actiy= ity dimension findings for psychologists.

The absence of such differences within the social worker group may reflect the relatively broad definition of social work practice compared to the other groups. That is, this absence of differences may reflect social work's relatively widespread, explicit acknowledgement of "counseling" as a term encompassing a broad range of activities - as social work itself does -- and as including the perhaps more difficult and complex processes which some appear to associate primarily with "psychotherapy."

Other historical and sociopolitical events may be relevant to differences in ratings of Individual Counseling and Individual Psychotherapy within the professional groups. Clinical psychology has historically been more aggressive than social work in its effort to develop as an autonomous mental health care profession independent of psychiatry and in its effort to assert its right to provide psychotherapy without the supervision of psychiatry (Goode, 1960; Orne, 1975). This may help to explain the more positive eyglua= tien and more extreme actiyity within-group ratings psychologists give Individual Psychotherapy compared to Individual Counseling, while social workers as a group indicate no such differences between these methods. That is, clinical psychologists may in some respects be asserting their pro- 
fessional rights and competence by indicating that they regard Individual Psychotherapy as more positive in eyalua= tion and more active than Individual Counseling. Perhaps in registering such values they are asserting their association with a process (psychotherapy) historically regarded in the United states as simultaneously demanding, complex and positive in outcome, as well as once completely within the province of psychiatry (Orne, 1975), but which clinical psychology, despite much conflict with psychiatry, has successfully defined as within its professional sphere (Rogers, 1980). In contrast, the social work profession historically has been more willing to function professionally within a context of psychiatric supervision (Goode, 1960; strauss et ale, 1964) and may not feel a need to assert professional autonomy and worth in this particular way.

The finding that psychologists see Individual Counseling as less active than Individual Psychotherapy, while the other groups see no such difference, may be due to a combination of such phenomena as: the confusion (and possibly lower status) associated with the term "counseling" relative to "psychotherapy" in the psychologists' professional reference group, social workers' apparently equal professional acceptance of both Individual psychotherapy and Individual Counseling, and a possibly inactive psychoanalytic psychiatric treatment orientation in conjunction with a medical model understood to have passive components which may de- 
emphasize psychiatrists" perceptions of "activity" in Individual Psychotherapy.

That is, the fact that psychiatrists perceive Individual Psychotherapy and Individual Counseling as being equally active, although they give Individual Psychotherapy a more positive evaluation than Individual Counseling, may be related to psychiatrists' general perceptions of the actiyity level involved in providing individual mental health treatment, as elaborated directly below.

\section{Intergroup Differences}

The findings that psychologists and social workers see Individual Psychotherapy as more actiye than do psychiatrists, and that social workers see Individual Counseling as more ective than do psychiatrists, may be a function of the psychoanalytic emphasis often found in psychiatry and/or of use of the medical model itself. A psychoanalytic orientation could imply treatment in which the role of the therapist could tend toward that of a passive/interpretive focus of transference, rather than supporting the more active/ direct interpersonal exchange legitimized in many nonpsychoanalytic approaches (Corsini, 1973; Kovel, 1976; May, 1967 ; Rogers, 1980$)$.

Moreover, the medical model, which at some level seems likely to be invoked by psychiatrists providing Individual Psychotherapy, inherently implies some passivity (inactiv- 
ity) on the part of the patient relative to the authority figure (psychiatrist). Thus it seems possible that for the psychiatrist and/or the patient, "activity" may be deemphasized in Individual Psychotherapy as it is perceived by the psychiatrist professional group.

Another notable intergroup difference is the social workers' more positive evaluation of Individual Counseling than the psychiatrists'. This may be due to the professional acceptance of a counseling function by social workers while a similar broad acceptance of the term "counseling" as a generally accepted description of professional function has not been found for psychiatrists.

This apparent difference in professional group acceptance of a counseling function may account for the contrasta in Individual Counseling-Individual Psychotherapy difference scores for these two groups (Table XIII). This comparison indicates that social workers see these two modalities as being significantly closer together on the evoluation dimension than do psychiatrists, although no such score difference is found for psychologists compared to social workers or to psychiatrists on this dimension. The fact that social workers appear to see these methods as being more closely related than do psychiatrists may be due to social work's broad acceptance of both methods in marked contrast to psychiatry. Not only does psychiatry not appear to acknowledge "counseling" as within its professional sphere, 
psychiatry also clearly tends to emphasize (both in this study and in the literature) the place of "psychotherapy" as the highest-valued professional endeavor.

Similar reasoning may be relevant to the finding that Individual Counseling-Individual Psychotherapy difference scores for the social worker and psychologist groups indicate that the social workers see these modalities as closer together on the ectivity dimension than do psychologists. Social work's apparent broad acceptance of both methods through an extensive historical association with a "counselor" role as well as currently actualized aspirations to a "psychotherapist" role may limit their perceptions of distinctions between the methods Individual Counseling and Individual Psychotherapy. The relatively strong multimodality, multidimensional affirmation of Individual Psychotherapy by psychologists, perhaps a result of their aggressive claim to the "psychotherapist" role once solely claimed by psychiatry, may be related to the difference score activ= ity dimension contrast of psychologists with social workers. Also perhaps psychologists, being more research-trained and thus more explicitly cause-and-effect oriented than social workers, see Individual Psychotherapy as a process wherein variables effecting positive change are actively manipulated, in contrast to a less clear perception of the Individual Counseling process. 
Although psychologists, like psychiatrists, hold "psychotherapy" in high esteem, they do so without ignoring the "counseling" function. The fact that counseling psychology is widely acknowledged as a legitimate psychological discipline may be a reason that psychologists exaluate Individual Counseling more positively than do psychiatrists. Such clear professional affirmation by psychologists, combined with social work's professional acceptance, may be a reason that a comparison between these groups indicates that they eyaluate Individual Counseling quite similarly.

\section{Cenclusions}

In general, it appears that to a limited extent the impressions and implications of the literature regarding differences between Individual Counseling and Individual Psychotherapy have been only somewhat supported. There is some tendency in various ways to see Individual Counseling as perhaps a lesser treatment process than Individual Psychotherapy. However, the fact that such differences are not consistent over all groups and (EPA) dimensions is a lso consistent with the controversy in the literature over whether such differences exist at all.

It seems that some differences between the processes may well exist, but with insufficient strength, consistency and clarity to be of more than questionable usefulness in differentiating these treatments or those who provide them. 
Overall, firm distinctions separating the methods Individual Counseling and Individual Psychotherapy as clearly different processes have not been found.

\section{SUMMARY AND CONCLUSIONS}

Psychologists and social workers are quite similar to each other here in the evaluation of mental health treatment modalities, but differ markedly from psychiatrists. This differentiation of psychiatrists from the other two groups may be accounted for most parsimoniously in terms of the relative acceptance by each group of treatment methods which can be viewed as being within its professional sphere, and the relative nonacceptance by each group of methods which may be perceived as being outside the scope of that profession. In particular, it appears that the professions can be differentiated by their relative acceptance of treatment methods which are subsumed under the medical model or which are independent of it. Both professionally autonomous/ legitimate access and subscription/proscription of the medi cal model may be independent or simultaneously operating factors influencing the professionals' evaluations of treatments. That is, both professional self-interest and theoretical/training factors may affect professionals' attitudes toward mental health treatment methods. Data here are not sufficient to decide this question of possible causality. 
Psychiatrists are, relative to the other groups, most accepting of treatment methods to which they historically have had legitimate access and which may be readily understood through medical-model concepts. They are least positively inclined toward methods for which they are least likely to be trained and for which the medical model is of little direct relevance. On the other hand, psychologists and social workers are relatively negative toward modal ities which are medical-model-based and which necessarily imply some physician involvement (i.e., modalities to which they have no legitimate autonomous access). Moreover, they are relatively positive toward modalities which may be understood clearly as being within their (nonmedical) professional purview and for which the medical model appears irrelevant.

It seems plausible that these attitude differences may result in clinical psychologists and social workers being more likely than psychiatrists to emphasize counseling and family-oriented treatment but to reject medication and hospitalization as mental health treatment options. Conversely, findings here imply that psychiatrists may be more likely than clinical psychologists or social workers to recommend medication or hospitalization as appropriate psychiatric treatments and less likely than the other two groups to support counseling or family-oriented methods as appropriate approaches to mental health care. Intergroup 
differences in extremeness of ratings (range scores) emphasize the strength of these attitudinal differences and an apparently firmmedical-nonmedical dichotomy among these mental health professionals. The relatively extreme rejection of necessarily medically oriented treatment by the nonmedical professionals and their relative enthusiasm for the most clearly nonmedical approaches is underscored.

In terms of the professional groups' scores with reference to absolute neutrality as defined by the midpoints of the semantic differential scales, the psychiatrist group demonstrates a basically positive attitude toward all modalities, while psychologists and social workers are negative or cautiously neutral about the clearly medical methods but much more positive about the other methods. In terms of nonrelative scores, no group radically rejects any treatment method. However, the nonrelative group scores support the idea that the psychiatrists' professional selfconcept includes the view that they may use (and therefore do accept) virtually all treatment methods. On the other hand, the professional training of psychologists and social workers and the sociopolitical constraints on their (medical) treatment may result in their reservations about treatments based on the medical model.

Although the groups did not differ in their positive at itudes toward Individual Psychotherapy, only psychiatrists and psychologists considered this the consistent 
treatment of choice. Thus, social workers, who preferred Individual Psychotherapy only over Psychiatric Hospitalization and Psychiatric Medication, may be more even-handed in accepting a broad range of (nonmedical) treatment approaches than the other groups. Unfortunately, lack of a single clear definition of "Individual Psychotherapy" throughout professional literature and practice hampers finalization of conclusions.

Nonetheless, this confirmation of the hypothesized generally favorable broad professional perception of Individual psychotherapy raises questions about substantive reasons for such perceptions. Obvious possibilities include both that this method is the genuine treatment of choice due to its overall effectiveness and applicability, and/or that this method is overvalued (and perhaps thus overused) due to its benefits to the care provider irrespective of benefits to the client. Perhaps this attitude is an historical artifact which is promulgated out of ignorance and necessary pragmatism, for want of sufficiently extensive outcome/ effectiveness research which could match clients, therapists, treatment problems and methods for optimum results. Multiple definitions of "Individual Psychotherapy" are obvious confounds to sorting out questions of the most appropriate place of this method in mental health care provision. This research only marginally touches on such questions. However, it does empirically confirm the existence 
of markedly favorable professional attitudes toward Individual Psychotherapy. Thus, these findings raise the issue of the appropriateness of the implied weighting of treatment provision toward Individual Psychotherapy, when considered in the overall context of provision of optimal mental health care.

There is some indication that professional mental health care providers regard Individual Psychotherapy as a more positive treatment method than Individual Counseling. However, a clear-cut and unambiguous differentiation between these methods across all the professional groups is not supported. In appears that Individual Psychotherapy may be markedly distinguished from Individual Counseling by psychatrists in that the former may be seen as a legitimate medical-model treatment option while the latter may not be so regarded. In contrast, social workers appear to see Individual Counseling as being more similar to Individual Psychotherapy then the psychiatrists, and in some ways social workers also see these modalities as more similar than do the psychologists. Indications of a minimization of differences in these two methods by the social worker group may be due to a long-standing identification of social work with counseling in a broad sense and to the aspirations of this professional group ( 1 ike the other two groups) to the professional autonomy and status afforded by the practice of Individual Psychotherapy. However, neither a firm melding 
of or distinction between the modalities Individual Counseling and Individual Psychotherapy as treatment processes was indicated here.

The preceding attitudinal findings imply that biases exist regarding treatment methods among mental health professional groups. Although none of the groups examined here completely rejects any treatment method, relative differences in approval of some modalities are substantial and noteworthy. Thus, it appears that interprofessional differences in treatment recommendations are likely to occur. In particular, psychologists and social workers may be most likely to differ from psychiatrists in terms of their relative favoring of some apparently nonmedical treatment methods and caution regarding the most purely medical approaches, while psychiatrists may be relatively reluctant to support the more clearly nonmedical treatment efforts.

To some extent, such differences may be positive for the recipients of services so long as their access to services of all the mental health care professions is equally maintained, since these interprofessional attitudinal differences may result in the availability of more diverse treatment options than wouldexist if professional attitudes were homogeneous, and since these differences may result in interprofessional checks on the overuse of any single treatment perspective. It is likely that the interprofessional conflict which seems inherent in such attitude 
differences may be helpful in provoking a more rigorous examination of treatment outcome and effectiveness than would otherwise occur. In fact, the interprofessional differences found here may be evidence of an instance of the kind of "conflict of paradigm" necessary for scientific progress to occur (cf. Kuhn, 1970).

Such issues regarding the meaning and implications of the present findings appear to be most clearly formed in terms of professional training, theoretical views, treatment options and practices, and possible self-interest of the separate mental health care professions. The clearly evident contrast of the psychiatrist group vis-a-vis the social workers and psychologists indicates a central professional concern and possible dividing-line: the place of the medical model in mental health care. The relative attitudinal homogeneity found here of the psychologist and social worker groups poses questions regarding other empirical grounds for professional differentiation and the nature of these professions as separate entities. A noteworthy possible constraint on these findings is the generalizability of a random sample of professionals from a major metropolitan area of the northwestern United States to other areas. Also of interest are the relationships of such variables as extent of clinical experience and theoretical orientation to at itudes toward mental health treatment methods. Such issues may best be dealt with through further research. 
Most importantly, findings here clearly indicate the worth of further study examining the final effect of mental health professionals' treatment method biases on the consumers of mental health care. It is to be hoped that Singer's (1979) concerns regarding the existence - and the potential destructiveness - of biased mental health treatment provision, given credence here, will not be further substantiated. 


\section{REFERENCES}

Ackerman, N.W. The future of family psychotherapy. In N.W. Ackerman, F.L. Beatman \& S.N. Sherman (Eds.), Expanding theory and practice in family therapy. New York: Family Service Association of America, 1967.

Adams, S. \& Orgel, M. Through the mental health maze: a consumer's guide to finding a psychotherapist. Washington: Health Research Group, 1975 .

American Medical Association, American Psychiatric Associa$t i o n$, American Psychoanalytic Association. Of $f$ icial notice: resolution on the relations of medicine and psychology. American Jeurnal of Esychiatry, 1954, I I (5), 385-386.

Antonio, J.D. \& Innes, J.M. Attribution biases of psychiatrists and psychologists. Esychelegiesl Reperts, 1978, 43, 1149-1150.

Arkava, M.L. Behayier modification: a precedural guide for social werkers. Missoula: University of Montana Department of Social Work, 1973.

Armor, D.J. \& Klerman, G.L. Psychiatric treatment orientations and professional ideology. Journal of Heglth and Social Behoyior, 1968, 9, 243-255.

Baker, F. \& Schulberg, H.C. The development of a community mental health ideology scale. Community Mental Health Jeurnal, 1967, 3, 216-225.

Bascue, L.O. \& Zlotowski, M. Psychologists' practices related to medication. Journal of clinical Rsychology, 1980,36 ( 3 ) , 821-825.

Beck, B.M. Yeur future in secial work. New York: Richard Rosen Press, 1964.

Bell, J.E. Eamily therapy. New York: Jason Aronson, 1975.

Berdie, R.E. Counseling. Annual Reyiew of Rsychelogy, $1959,10,345-370$. 
Blaney, P.H. Implications of the medical model and its alternatives. American Journal of Rsychiatry, 1975, LIV, 358-363.

Block, J. Studies in the phenomenology of emotions. Jour= nal of Abnormal and Social Psycholegy, 1957, LIV, 358363 .

Boehm, W.W. The social worker as a psychotherapist: functions and educational preparation. In N.P. Dellis \& H.K. Stone (Eds.), The training of psychethergoists: multidisciplinary approach. Baton Rouge: Louisiana State University Press, 1960.

Bowden, C.L., Humphrey, F.J., \& Thompson, G.G. Priorities in psychiatric residency training. American Jeurnal of Rsychiatry, 1980,137 (10), 1243-1246.

Brayfield, A.H. Counsel ing psychology. Annugl Reyiew of Esycholegy, $1963,14,319-350$.

Brody, E.B. The development of the psychiatric resident as a therapist. In N.P. Del lis \& H.K. Stone (Eds.), The training of psychotherapists: a multidisciplinary approach. Bat on Rouge: Louisiana State University Press, 1960 .

Carkhuff, R.R. \& Berenson, B.G. Beyend counseling and Rsy= chotherapy. New York: Holt, Rinehart and Winston, 1967 .

Casariego, J.I. \& Greden, J.F. Perceptions of treatment value, therapeutic orientation, and actual experience of psychiatric residents. Comprehensive Rsychiatry, $1978,19,241-248$.

Chance, E., Arnold, J., \& Tyrrell, S. Professional background and themes used in clinical case description. Human Relations, $1962,15,53-61$.

Charatan, F.B. \& Rosenblatt, I. Psychotherapy: the views of psychiatrists from Scotland and Nassau County, New York. American Journal of Esychiatry, 1969, 125 (8), $1120-1122$.

Cohen, J. \& Struening, E.L. Opinions about mental illness: mental hospital occupational profiles and profile clusters. Psycholegical Reports, 1963, 12, 111-124. 
Connaughton, J.P. Psychiatry. In P.J. Vallettutti \& F. Chr is taplos (Eds.), Interdisciplinary appreaches to human services. Baltimore: University Park Press, 1977 .

Corsini, R. (Ed.). Current psychetherapies. Itasca, Ill.: F.E. Peacock, 1973 .

Coryel l, W. \& Wetzel, R.D. Attitudes toward issues in psychiatry among third-year residents: a brief survey. American Journal of Rsychiatry, 1978, 135 (6), 732-735.

Cottle, T.J. \& Whitten, P. (Eds). Rsychotheregy: current perspectiyes. New York: New Viewpoints, 1980 .

Day, M. \& Semrad, E.V. Schizophrenic reactions. In A.M. Nicholi, Jr. (Ed.), The Haryard guide to modern psychi= atry. Cambridge: Harvard University Press, 1978.

Derner, G.F. An interpersonal approach to training in psychotherapy. In N.P. Del lis \& H.K. Stone (Eds.), The training of psychetherapists: a multidisciplinary approach. Baton Rouge: Louisiana State University Press, 1960 .

Douglas, $T$. Group precess in social work: a theoretical synthesis. New York: John Wiley and Sons, 1979.

Eaton, J.S., Jr. \& Goldstein, L.S. Psychiatry in crisis. In T.J. Cottle \& P. Whitter (Eds.), Psychotherapy: current perspectipes. New York: New Viewpoints, 1980 .

Fishbein, M. A consideration of beliefs, at itudes, and their relationship. In I.D. Steiner and M. Fishbein (Eds.), Current studies in seciol psycholegy. New York: Holt, Rinehart \& Winston, 1965.

Fontana, A.F., Gessner, T. \& Lorr, M. How sick and what treatment: patient presentations and staff judgments. American Journal of Psychotherapy, 1968, 22, 26-34.

Fox, R.E. Family therapy. In I.B. Weiner (Ed.), Clinical methods in Dsychelogy. New York: John Wiley and Sons, 1976 .

Garfield, S.L. \& Kurtz, R. A survey of clinical psychologists: characteristics, activities and orientations. Clinicel Psychologist, 1974,28 (1), 7-10. 
Goffman, E. Asylums: essays on the social situlation of mental patients and other inmates. Garden City, N.Y.: Doubleday, 1961 .

Goldman, R.K. \& Mendelsohn, G.A. Psychotherapeut ic change and social adjustment: a report of a national survey of psychotherapists. Journal of Abnermel Psychelegy, 1969,74 (2), 164-172.

Goldschmid, M.L. \& Domino, G. Differential patient perception among various professional disciplines. Jeurnal of Consulting Rsycholegy, 1967, 31 (6), 548-550.

Goode, W.J. Encroachment, charlatanism, and the emerging profession: psychology, sociology and medicine. Amer= ican Seciological Reyiew, 1960, 25, 902-914.

Granger, S.G. Psychologists' prestige rankings of 20 psychol ogical occupations. Journal of Counseling Psychelegy, 1959, 6, 183-188.

Grayson, H.M. \& Tolman, R.S. A semantic study of concepts of clinical psychologists and psychiatrists. Journal of Abnormal and Social Rsycholegy, 1950, 45, 216-231.

Greden, J.F. \& Casariego, J.I. Controversies in psychiatric education: a survey of resident's attitudes. American Journal of Esychiatry, 1975, 132 (3), 270-274.

Guze, S.B. The future of psychiatry: medicine or social science? Journal of Neryous and Mental Diseases, 1977 , 165 ( 4$), 225-230$.

Guze, S.B. Nature of psychiatric illness: why psychiatry is a branch of medicine. Comprehensile Rsychiatry, 1978,19 (4), 295-307.

Haley, J. Family therapy. In A.M. Freedman, H.I. Kaplan \& B.J. Sadock (Eds.), Comprehensiye textbook of psychi= atry (2nd ed.), 2. Baltimore: Williams and Wilkins, 1975 .

Hathaway, S.R. A study of human behavior: the clinical psychologist. American Psychologist, 1958, 13, 257265 .

Heiman, E.M. The future relationship of psychiatrists with other mental health professionals. Psychiatric

Qpinien, $1978,15(10), 25-30$. 
Heise, D.R. Some methodological issues in semantic differential research. Bsychelogiegl Bulletin, 1969, 72 (6), 406-422.

Henry, W.E., Sims, J.H. \& Spray, S.L. The fifth profession: becoming a psychotherapist. San Francisco: JosseyBass , 1971 .

Henry, W.E., Sims, J.H. \& Spray, S.L. Rublic and priyate liyes of psychotherapists. San Francisco: JosseyBass, 1973 .

Hersey, W.J., Jr. Social work. In P.J. Val lettutti \& F. Chr is tapl os (Eds.), Interdisciplinary approaches to human services. Baltimore: University Park Press, 1977 .

House, W.C., Miller, S.I. \& Schlachter, R.H. Role definitions among mental health professionals. Comprehensiye Rsychiatry, 1978, 19, 469-476.

Jenkins, J.J., Russel1, W.A. \& Suci, G.J. An at las of semantic profiles for 360 words. American Jeurnal of Psychelegy, 1958, $71,688-699$.

Kelly, G. The psychology of persengl constructs. New York: Norton, 1955.

Kerlinger, F. The semantic differential. In Eoundations of behavieral research. New York: Holt, Rinehart and Winston, 1967 .

Kissen, M. From group dynamics to group psychoanalysis: therapeutic applications of group dynamic understanding. In M. Kissen (Ed.), Erem group dynamies to group Rsycheanglysis. New York: John Wiley and Sons, 1976.

Klopfer, W.G. The psychelogical repert. New York: Grune \& Stratton, 1960 .

Kovel, J. A complete guide to therapy. New York: Random House, 1976 .

Krech, D., Crutchfield, R.S., \& Ballachey, E.L. Indiyidual in society: a textbook of social psychology. New York: MeGraw-Hill, 1962 .

Kuhn, T.S. The structure of scientific reyolutions (2nd ed.). Chicago: University of Chicago Press, 1970. 
Kurtz, R.M. \& Kaplan, M.L. Resident attitude development and the ideological commitment of the staff of psychiatric training institutions. Jeurnal of Medical Educa= tion, $1968,43,925-930$.

Lidz, T., Hotchkiss, G. \& Greenblatt, M. Patient-familyhospital interrelationships: some general considerations. In M. Greenblatt and D.J. Levinson (Eds.), The patient and the mental hespital. Glencoe, Ill.: The Free Press, 1957.

Lief, H.I. Training in broad spectrum psychotherapy. In N.P. De 11 is \& H.K. St one (Eds.), The training of psychotherapists: a multidisciplinary aporeach. Baton Rouge: Louisiana state University Press, 1960.

Lorei, T.W. Staff ratings of the relative importance of the consequences of release from or retention in a psychiatric hospital. Journal of Censulting and clinical Esychelogy, 1970,24 (1), 48-55.

Lubin, B. Group therapy. In I.B. Weiner (Ed.), Clinical methods in psychology. New York: John Wiley and Sons, 1976 .

Maguire, T.O. Semantic differential methodology for the structuring of attitudes. American Education Besearch Journal, 1973,10 (4), 295-306.

May, R. The art of counseling. Nashville: Abingdon Press, 1967 .

MeCrosky, J.C., Larson, C.E., \& Knapp, M.L. An introduction to interpersonal communication. Engl ewood Clif $\mathrm{s}$, N.J.: Prentice-Hall, 1971.

MePartland, J.S. \& Richart, R.H. Social and clinical outcomes of psychiatric treatment. Archiyes of Genergl Psychiatry, $1966,14,179$.

Meiers, J. Origins and deyelepment ef greup psychetherapy. 1930=1945. New York: Beacon House, Psychodrama Monographs No. $17,1946$.

Meissner, W.W. \& Nicholi, A.M., Jr. The psychotherapies: individual, family and group. In A.M. Nicholi, Jr. (Ed.), The Haryard guide to medern Rsychiatry. Cambridge: Harvard University Press, 1978. 
Meyer, H.J. Profession of social work: contemporary characteristics. In R. Morris (Ed.-in-Chief), Encyclepedia of seciol work, sixteenth issue, LI. New York:

National Association of Social Workers, 1971.

Miles, H.W. Discussion of Dr. Whitaker's paper. In N.P. Del 1 is \& H.K. Stone (Eds.), The training of psycho= therapists: a multidisciplinary approach. Bat on Rouge: Louisiana State University Press, 1960.

Mishara, B.L. \& Patterson, R.D. The censumer's handbook of mental health. New York: New American Library, 1977.

Mittel, N.S. Does the psychiatrist bring anything special to psychotherapy? Psychiatric Qpinien, 1978, 15 (4), 32-36.

Modlin, H.C. Psychiatric social service information. In A.M. Freedman, H.I. Kaplan \& B.J. Sadock (Eds.), Com= Rrehensiye textbook of Rsychiatry (2nd ed.), 1. Baltimore: Williams and Wilkins, 1975 .

Monroe, R.R. Discussion of Dr. Derner's paper. In N.P. Del 1 is \& H.K. Stone (Eds.), The training of esyche= therapists: a multidisciplinary approach. Baton Rouge: Louis iana State University Press, 1960.

Monte, C.F. Beneath the mask (2nd ed.). New York: Holt, Rinehart and Winston, 1980 .

Morrison, J.K. \& Hanson, G.D. Clinical psychologists in the vanguard: current attitudes toward mental illness. Rrefessienel Psychology, 1978, 9 (2), 240-248.

Morrison, J.K. \& Nevid, J.S. Attitudes of mental patients and mental health professionals about mental ill ness. Esychologicel Reports, 1976, 38, 565-566.

Mu 11 an, H. \& Rosenbaum, M. Greup psychetherapy theery and practice. New York: The Free Press, 1962 .

Myers, J.M. \& Rosen, H.B. Psychiatrists' current attitudes about psychiatric treatment. Comprehensiye Rsychiatry, $1966,7,232-239$.

Nacman, M. Social workers in mental health services. In J.B. Turner (Ed.-in-Chief), Encyclopedig of sociol work, seyenteenth issue, II. New York: National Association of Social Workers, 1977 . 
Napier, A.Y. \& Whitaker, C.A. The family crucible. New York: Harper and Row, 1978.

Nie, N.H., Hul 1, C.H., Jenkins, J.G., Steinbrenner, K. \& Bent, D.H. Statistical package for the social sciences (2nd ed.). New York: McGraw-Hill, 1975.

Northen, H. Socigl work with groups. New York: Columbia University Press, 1969.

Orne, M.T. Psychotherapy in contemporary America: its development and context. In S. Arieti (Ed.-in-Chief), D.X. Freedman \& J.R. Dryrud (Eds.), Americen handbook of psychiotry (2nd ed.), yolume 5i treatment. New York: Basic Books, 1975.

Osgood, C.E. Cross-cultural comparability in attitude measurement via multilingual semantic differentials. In I. Steiner and $M$. Fishbein (Eds.), current studies in secial psychelegy. New York: Holt, Rinehart and Winston, 1965 .

Osgood, C.E., Suci, G.J. \& Tannenbaum, P.H. The measurement of meaning. Chicago: University of Illinois Press, 1957 .

Osgood, C.E. \& Tannenbaum, P.H. The principle of congruity in the prediction of attitude change. Rsycholegieal Reyiew, $1955,62,42-55$.

Paterson, D.G. \& Lofquist, L.H. A note on the training of clinical and counseling psychologists. American Psychelegist, $1960,15,365-366$.

Patterson, C.H. Counseling. Annual Reyiew of Rsychelegy, $1966,17,79-110$.

Patterson, C.H. Psychotherapy in the school. In D.S. Arbuckle (Ed.), Counseling and Dsychotherapy, an eyer= view. New York: MeGraw-Hill, 1967.

Pepinsky, H.B. \& Meara, N.M. Student development and counseling. Annual Beyiew of Psychelogy, 1973, 24, 117150 .

Pinney, E.L., Jr. A first group Rsychotherapy beok. Springfield, Illinois: Charles C. Thomas, 1970.

Rie, H.E. Psychology, mental health and the public interest. Americen Psychologist, 1977, 32, 1-4. 
Riess, B.F. The selection and supervision of psychotherapists. In N.P. De $1 \mathrm{l}$ is \& H.K. St one (Eds.), The train= ing of psychotherapists: a multidisciplinary appreach. Baton Rouge: Louisiana State University Press, 1960.

Rogers, C.R. A way of being. Boston: Houghten Mifflin, 1980 .

Sackheim, G. The practice of clinical casework. New York: Behavioral Publications, 1974 .

Sadock, B.J. Combined individual and group psychotherapy. In A.M. Freedman, H.I. Kaplan \& B.J. Sadock (Eds.), Comprehensiye textbeek of psychigtry (2nd ed.), 2 . Baltimore: Williams and Wilkins, 1975.

Sarbin, T.R. On the futility of the proposition that some people be labelled "mentally ill." Jeurnal of Censulting Rsychelegy, 1967, 31, 447-453.

Schwab, J.J. Psychiatry's identity crisis. Rsychiatric Qpinien, $1978,15(10), 37-39$.

Shakow, D. Clinical psychology. In A.M. Freedman, H.I. Kaplan \& B.J. Sakock (Eds.), Comprehensiye textbeek of psychiotey (2nd ed.), 2. Baltimore: Williams and Wilkins, 1975 .

Shaw, F.J. Counseling. Annual Beyiew of Psychelegy, 1957, $8,357-376$.

Shearn, C.R. \& Fitzgibbons, D.J. Theoretical orientation of mental health professionals as a function of professional discipline and length of experience. Psyche= legical Beports, $1971,28,230$.

Shotwe 11 , A.M., Dingman, H.F. \& Tarjan, G. Need for improved criteria in evaluating job performance of state hospital employees. American Journal of Mental Defici= ency, $1960,65,208-213$.

Siegler, M. \& Osmond, H. Models of madness, models of medicine. New York: MacMillan, 1974.

Singer, M. Reflections of Family Therapists 1959-1979-1999. Remarks made at the Fourth Don D. Jackson memorial conference (Mental Research Institute), San Francisco, Augus t 4, 1979 .

Snider, J. \& Osgood, C. (Eds.). Sementic differential tech= nique: a seurceboek. Chicago: Aldine, 1969. 
Staats, A.W. \& Staats, C.K. Attitudes established by classical conditioning. Journal of Abnermal and Secial Esychelegy, 1958, 57, 37-40.

Stefflre, B. Function of theory in counseling. In B. Stefflre \& H.W. Grant (Eds.), Theories of counseling. New York: MeGraw-Hi 11, 1972 .

Stone, W.N., stein, L.S. \& Green, B.L. Faculty and resident commitment to varieties of psychiatric treatment. Archiyes of Genergl Psychiatry, 1971, 24, 468-473.

Strauss, A., Schatzman, L., Bucher, R., Ehrlich, D. \& Sabshin, H. Psychiatric ideologies and institutions. New York: The Free Press, 1964.

Sundberg, N.D., Tyler, L.E. \& Taplin, J.R. Clinical psychology: expanding horizons (2nd ed.). New York: Appleton-Century-Crofts, 1973.

Szasz, T.S. The problem of psychiatric nosology. American Journal of Eschiatry, 1957, 114, 405-413.

Tannenbaum, P.H. Mediated generalization of at itude change via the principle of congruity. Journal of Personglity and Social Rsyehology, 1966, II I, 493-499.

Tarrier, N. The future of the medical model. Journal of Neryous and Mental Disease, 1979, 167 (2), 71-73.

Tatsuoka, M.M. Multiyariate analysis. New York: Wiley, 1971 .

Trotter, S. Nader group releases first consumer guide to psychotherapists. American Rsychological Association Meniter, December, 1975 , pp. 1, 16 .

Truax, C.B. \& Carkhuff, R.R. Toward effective counseling and psychetherapy. Chicago: Aldine, 1967.

Turner, F.J. Psychesocial therapy. New York: The Free Press, 1978 .

Turner, J.B. (Ed.-in-Chief). Encyclopedis of social work. seyenteenth issue. New York: National Association of Social Workers, 1977 .

Tyler, L.E. Counsel ing. Annuel Beyiew of Psycholegy, 1958, $9,375-390$. 
Ursano, R.J. \& Dressler, D.M. Brief versus long-term psychotherapy: clinician attitudes and organizational design. Comprehensiye Rsychiatry, 1977, 18, 55-60.

Vance, F.L. \& Volsky, T.C., Jr. Counseling and psychotherapy: split personality or Siamese twins? American Esychologist, $1962,17,565-570$.

Warr, P.B. \& Knapper, C. The problem of measurement. In The perception of people and events. New York: John Wiley and Sons, 1968 .

We iner, I.B. (Ed.). Clinicel methods in psychology. New York: John Wiley and Sons, 1976.

Weinstein, L. Real and ideal discharge criteria. Mental Hospitals, $1964,15,680-683$.

We issman, H.N. Interprofessional differences in clinical decision-making with children. Esychology, $1969(a), 6$, $7-14$.

We issman, H.N. The psychiatric team as a differential decision-maker with child patients. Rsychological Beports, 1969 (b), 25, 11-17.

Weissman, H.N. The mental health team as a differential decision-maker for child patients: a national survey. Esychological Beports, 1975, 37, 643-650.

Wellner, A.M. Psychology. In P.J. Vallettutti \& F. Christaplos (Eds.), Interdisciplinary approaches to human seryices. Baltimore: University Park Press, 1977 .

Whiteley, J.M., Burkhart, M.Q., Harway-Herman, M. \& Whiteley, R.M. Counseling and student development. Annual Beyiew of Esychelogy, 1975, 26, 337-366.

Whittaker, J.K. Social treatment. Chicago: Aldine, 1974. Winter, W.D. Family therapy, research and theory. In C.D. Spielberger (Ed.), Current topies in clinical and com= munity Rsychelegy. New York: Academic Press, 1971.

Zilback, J.J. The family in family therapy. Journal of Child Rsychiatry, 1974, 13, 459-467. 
$\begin{array}{llllllll}\text { A } & \mathbf{P} & \mathbf{P} & \mathrm{E} & \mathrm{N} & \mathrm{D} & \mathrm{I} & \mathrm{X}\end{array}$ 
INSTRUCTIONS FOR COMPLETING THE SEMANTIC DIFFERENTIAL

RATING SCALES*

The purpose of this study is to measure the mean= ings of certain concepts by having you judge these concepts against a series of descriptive scales. In taking this test, please make your judgments on the basis of what these concepts mean to you. On each page you will find a different concept and beneath is a set of scales. You are to rate the concept on each of these scales in the order given. Here is how you are to use these scales:

If you feel that the concept at the top of the page is yery closely related to one end of the scale, you should place your check-mark as follows:

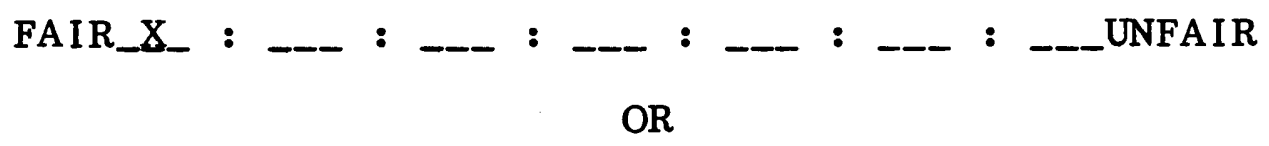

FAIR___ : __ : __ : ___ : _-_ : _- : _X_UNFAIR 。

If you feel that the concept is guite clesely related to one or the other end of the scale (but not extremely), you should place your check-mark as follows:

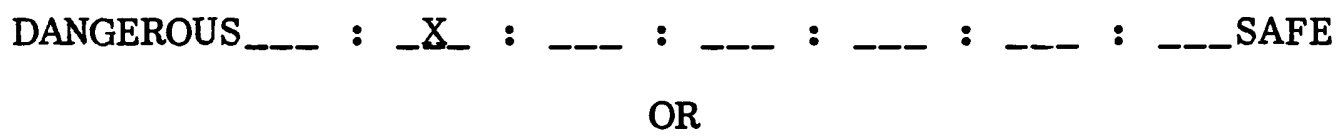

DANGEROUS ___ : ___ : ___ : ___ : ___ : _X_ : ___SAFE

If the concept seems enly slightly related to one or the other end of the scale (but is not really neutral), then you should check as follows:
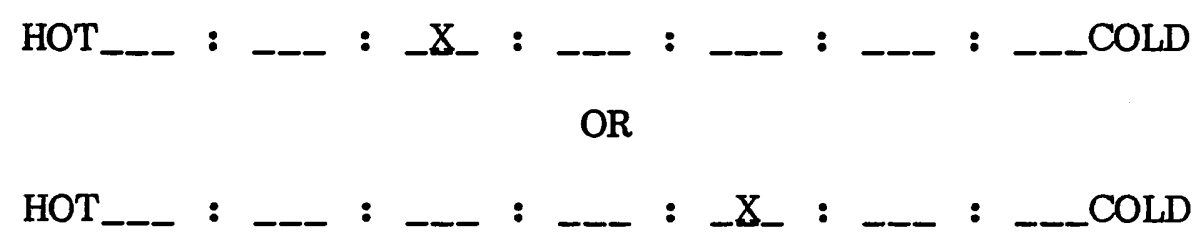

*As found in Osgood, Suci, and Tannenbaum, 1957 
The direction toward which you check, of course, depends upon which of the two ends of the scale seemmost characteristic of the thing you are judging. If you consider the concept to be neutral on the scale, both sides of the scale equally associgted with the concept, or if the scale is completely irreleyant, unrelated to the concept, then you should place your check-mark in the middle space:

SMALL___ : __ : ___ : _X_ : ___ : __ : ___LARGE

IMRORTANT: (1) Place your check-marks in the middle of spaces, not on the boundaries:

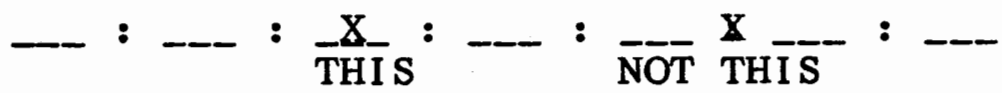

(2) Be sure you check every scale for every concept -- do net emit any.

(3) Never put more than one check-mark on a single scale.

Work at a fairly high speed through this test. Do not worry or puzzle over individual items. It is your first impressions, the immediate "feelings" about the items, that we want. On the other hand, please do not be careless, because we want your true impressions. Do net look back and forth through the items. Make each item a separate and indepen= dent judgment. Do not try to remember how you checked similar items earlier in the test.

NOTE: Please use the "concept definitions" on the following page to define concepts. 


\section{CONCEPT DEEINITIONS}

Indiyidual counseling: one-to-one meetings on a regular basis between a client and a mental health professional who ordinarily describes his or her treatment activity as "counseling."

Indixidugl Psychotherapy: one-to-one meetings on a regular basis between a client and a mental health professional who ordinarily describes his or her treatment activity as "psychotherapy."

Group Therapy: use of any therapeutic model (excluding medication) involving at least three unrelated persons and a therapist meeting regularly as a group for the purpose of producing positive psychological change in members.

Eamily Therapy: psychological intervention (excluding medication) with whole families or certain family members in order to improve family functioning.

Psychiatric Medication: patient-caregiver contact for the primary purpose of caregiver dispensation or regulation of medication prescribed to produce positive psychological change in the patient.

Esychiatric Hospitalization: voluntary or mandatory patient confinement to a psychiatric hospital or ward in order to produce positive psychological change in the patient. 
EXAMPLE OF THE SEMANTIC DIFFERENTIAL SCALES USED TO RATE TREATMENT MODALITIES:

\section{INDI VIDUAL PSYCHOTHERAPY}

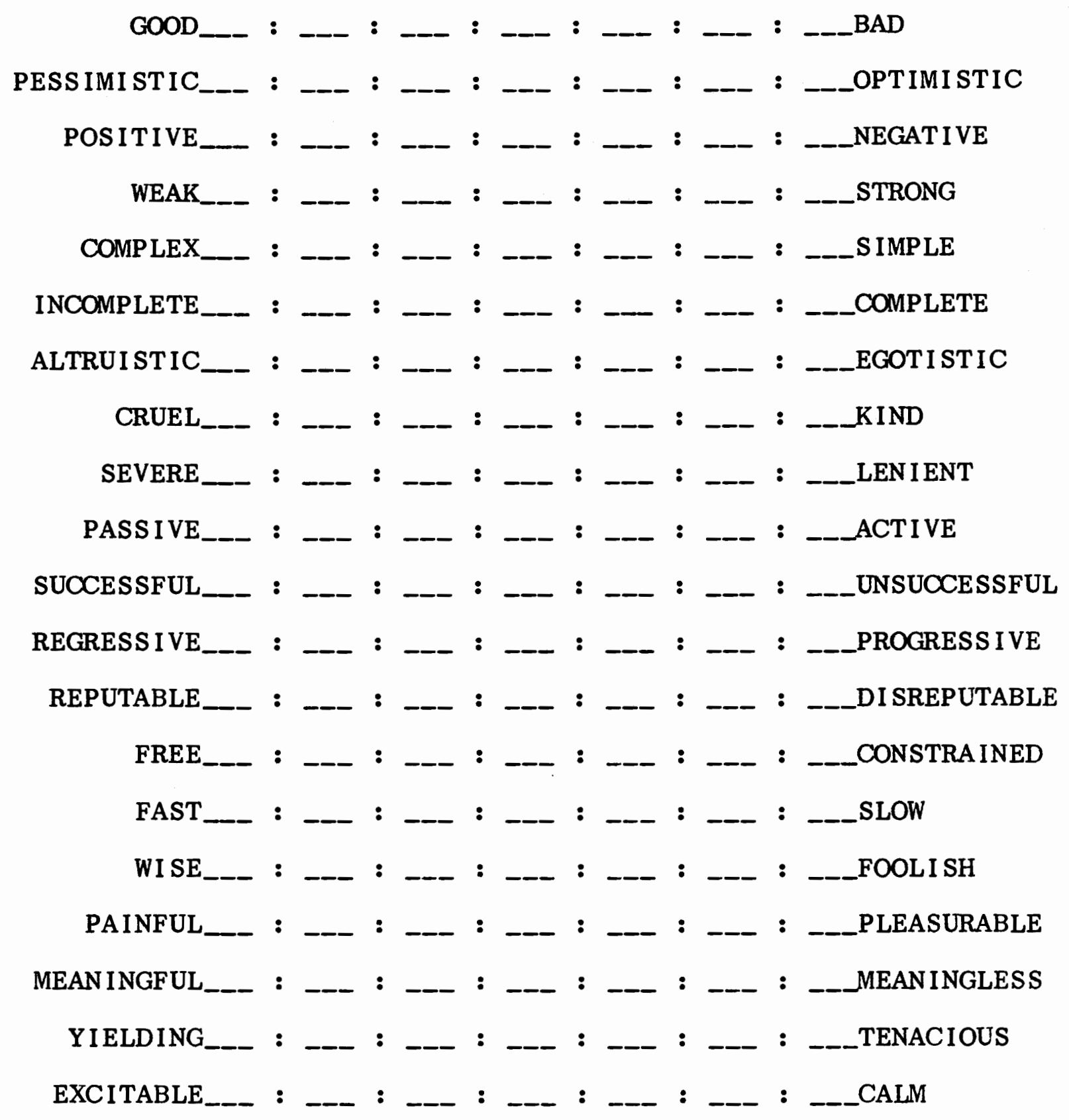

